Review

\title{
Photocatalytic Water Treatment by Titanium Dioxide: Recent Updates
}

Manoj A. Lazar ${ }^{1,2, *}$, Shaji Varghese ${ }^{3}$ and Santhosh S. Nair ${ }^{1,2}$

1 School of Applied Sciences and Engineering, Monash University, Churchill VIC, 3842, Australia; E-Mail: santhosh.nair@monash.edu

2 School of Chemistry, Monash University, Clayton VIC, 3800, Australia

3 Dipartimento di Scienze Chimiche e Geologiche, Università di Cagliari, Complesso Universitario Monserrato, CA 09042, Italy; E-Mail: shajivarg@ gmail.com

* Author to whom correspondence should be addressed; E-Mails: manoj.ainikalkannath@monash.edu or manojlazar2005@gmail.com; Tel.: +61-3-990-26411; Fax: +61-3-990-26738.

Received: 7 October 2012; in revised form: 7 December 2012 / Accepted: 10 December 2012 / Published: 19 December 2012

\begin{abstract}
Photocatalytic water treatment using nanocrystalline titanium dioxide (NTO) is a well-known advanced oxidation process (AOP) for environmental remediation. With the in situ generation of electron-hole pairs upon irradiation with light, NTO can mineralize a wide range of organic compounds into harmless end products such as carbon dioxide, water, and inorganic ions. Photocatalytic degradation kinetics of pollutants by NTO is a topic of debate and the mostly reporting Langmuir-Hinshelwood kinetics must accompanied with proper experimental evidences. Different NTO morphologies or surface treatments on NTO can increase the photocatalytic efficiency in degradation reactions. Wisely designed photocatalytic reactors can decrease energy consumption or can avoid post-separation stages in photocatalytic water treatment processes. Doping NTO with metals or non-metals can reduce the band gap of the doped catalyst, enabling light absorption in the visible region. Coupling NTO photocatalysis with other water-treatment technologies can be more beneficial, especially in large-scale treatments. This review describes recent developments in the field of photocatalytic water treatment using NTO.
\end{abstract}

Keywords: titanium dioxide; advanced oxidation process; photocatalysis; water treatment; degradation; Langmuir-Hinshelwood kinetics; photocatalytic reactor; doping 


\section{Introduction}

Realizing the importance of keeping our planet clean, researchers are actively working for eco-friendly alternative technologies for all areas of daily life. Sustainable energy production and pollutant destruction are two of the areas in which intense research is being carried out. Semiconductor-mediated photocatalysis is a well-established technique for pollutant degradation and hydrogen (clean fuel) production by water splitting. Photocatalysis can be defined as a "catalytic reaction involving the production of a catalyst by absorption of light" [1]. The appropriate positioning of valence (VB) and conduction (CB) bands in semiconductors (Figure 1a) makes them suitable materials for the absorption of light and photocatalytic action. Nanocrystalline titanium dioxide (NTO) is a multifunctional semiconductor photocatalyst that can be an energy catalyst (in water splitting to produce hydrogen fuel), an environmental catalyst (in water and air purification), or an electron transport medium in dye-sensitized solar cells (Figure 1b) [2-5]. Compared to other available semiconductor photocatalysts, NTO is unique in its chemical and biological inertness, photostability (i.e., not prone to photoanodic corrosion), and low cost of production [6]. Photocatalytic water and air purification using NTO is a predominant advanced oxidation process (AOP) because of its efficiency and eco-friendliness. Homogeneous photo-Fenton technique is another efficient AOP for the oxidation of water contaminants $[7,8]$. However, the photo-Fenton process requires the use of ferrous sulfate $\left(\mathrm{FeSO}_{4}\right)$ and hydrogen peroxide $\left(\mathrm{H}_{2} \mathrm{O}_{2}\right)$. For example, in the photo-Fenton oxidation of catechol, $\mathrm{H}_{2} \mathrm{O}_{2}\left(2000 \mathrm{mg} \mathrm{L}^{-1}\right)$ and $\mathrm{FeSO}_{4}\left(500 \mathrm{mg} \mathrm{L}^{-1}\right)$ were used in the experiment that reported the highest activity [7]. In contrast, NTO photocatalysis may not require any additional reagents beyond the NTO catalyst.

Figure 1. (a) VB and CB positions in metals, semiconductors, and insulators; (b) Tree diagram showing applications of $\mathrm{TiO}_{2}$.

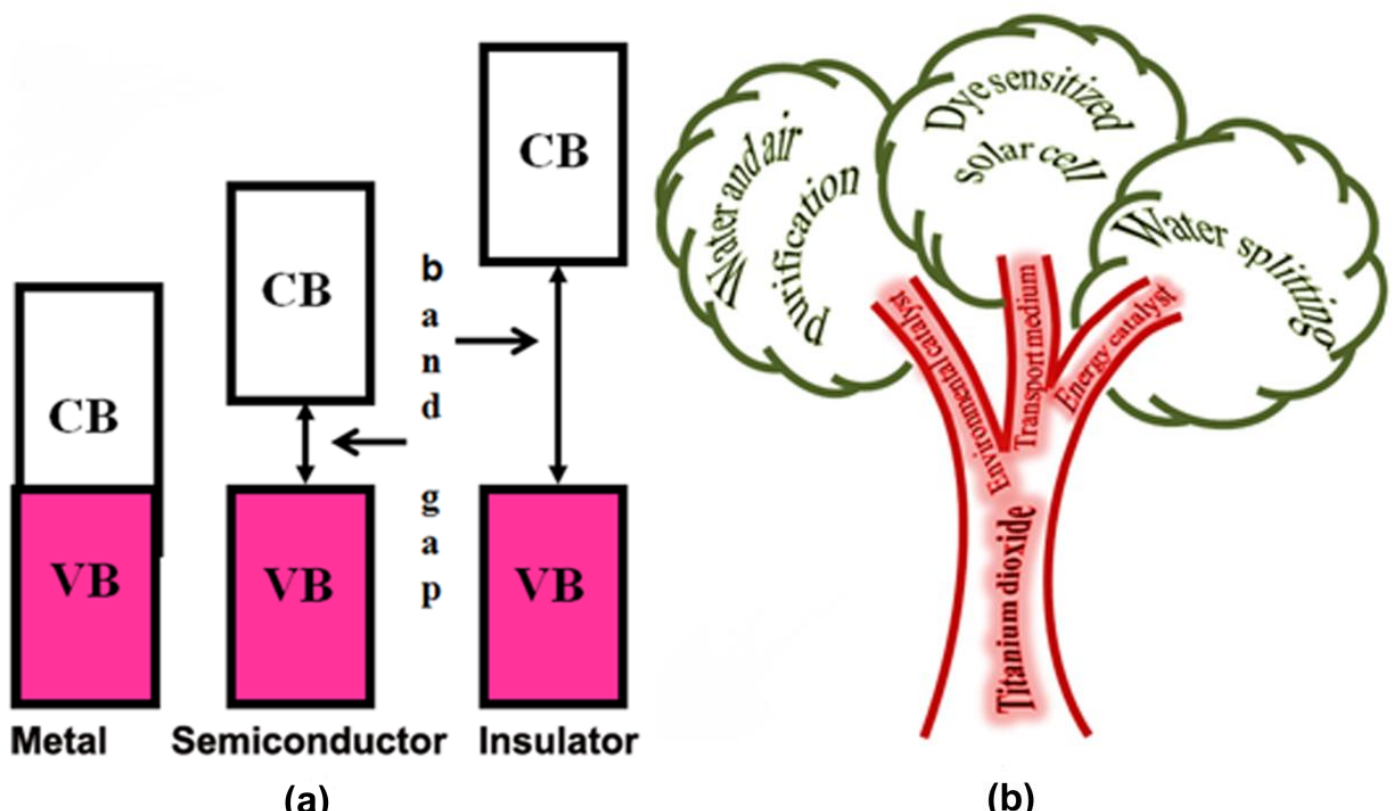

(a)

(b)

The spectrum of compounds that are susceptible to the destructive power of NTO photocatalysis is remarkable, comprising families of dyes, pesticides, herbicides, pharmaceuticals, cosmetics, phenolic compounds, toxins, and more. Recent examples of compounds photocatalytically degraded by NTO 
are given in Table 1. It is obvious from the table that researchers are focused on the photocatalytic degradation of real pollutant systems, such as cosmetics and pharmaceutical wastewaters [9,10], paper mill wastewater [11], grey water [12], and municipal wastewater [13]. Cheaper sources of $\mathrm{TiO}_{2}$, such as bulk-synthesized $\mathrm{TiO}_{2}$ pigment [14] and iron-containing industrial $\mathrm{TiO}_{2}$ by-products [15], have been explored for the photocatalytic degradation of phenol and humic acids. Interestingly, their activities were found to be comparable with those of the commercially available Degussa P25 $\mathrm{TiO}_{2}$ photocatalyst, the benchmark $\mathrm{TiO}_{2}$ photocatalyst for all applications. A report by Kim et al. describes the successful, elegant, and simultaneous use of NTO as both an energy and an environmental photocatalyst [16]. Their surface-fluorinated and -platinized NTO catalyst generated hydrogen gas when degrading 4-chlorophenol and bisphenol compounds. The selective degradation of contaminants is another promising area in photocatalytic water treatment. Selective degradation could be useful for mixtures of highly toxic pollutants in low concentrations and less harmful compounds in higher concentrations $[17,18]$. The former can be degraded by means of NTO photocatalysis, whereas the latter can be removed by less-expensive biological wastewater treatments [18]. In addition, valuable compounds must be recovered from wastewater; selective photocatalysis can be a useful tool. Recently, one of the authors reported the complete selective degradation of methyl orange and methylene blue dyes by base-modified nanocrystalline anatase (the most active form of $\mathrm{TiO}_{2}$ ) photocatalysts [19]. Among the two sol-gel-derived anatase photocatalysts, TSC60, with positive surface charge, selectively adsorbed and degraded the anionic dye methyl orange. In contrast, the second catalyst, TAH60, with negative surface charge, showed selective adsorption of the cationic dye methylene blue, followed by its degradation, from an aqueous mixture containing methyl orange and methylene blue dyes.

\section{Mechanism and Kinetics}

Photocatalytic destruction of pollutants in aqueous solutions using NTO is facilitated mainly by a series of hydroxylation reactions initiated by hydroxyl radicals $(\cdot \mathrm{OH})$ [20-26]. Possible modes of $\cdot \mathrm{OH}$ generation during NTO photocatalysis are shown in Figure 2. Upon UV light illumination, electron-hole pairs are formed in the NTO semiconductor photocatalyst. Holes are positive charges, which when in contact with water molecules, produce $\cdot \mathrm{OH}$ and $\mathrm{H}^{+}$ions. Electrons react with dissolved oxygen to form superoxide ions $\left(\mathrm{O}_{2}^{-} \cdot\right)$, which react with water molecules to produce hydroxide ions $\left(\mathrm{OH}^{-}\right)$and peroxide radicals $(\cdot \mathrm{OOH})$. Peroxide radicals combine with $\mathrm{H}^{+}$ions to form $\cdot \mathrm{OH}$ and $\mathrm{OH}^{-}$, and holes oxidize $\mathrm{OH}^{-}$to $\cdot \mathrm{OH}$. Thus, all species eventually facilitate the formation of $\cdot \mathrm{OH}$, and these radicals attack the pollutants present in the aqueous solution.

Medanna et al. reported [20] the formation of 51 stable intermediates in the photocatalytic degradation of the mosquito repellent $N, N$-diethyl-m-toluamide (DEET) using titanium dioxide under simulated solar light. Using a technique that coupled high-performance liquid chromatography with high-resolution mass spectrometry, they also identified several isomeric species. The degradation of DEET began with $\cdot \mathrm{OH}$-mediated mono- and polyhydroxylation reactions, followed by the oxidation and ring-opening reactions of intermediates. All the identified intermediates underwent complete mineralization after $4 \mathrm{~h}$ irradiation. The $\cdot \mathrm{OH}$-initiated photocatalytic oxidation of quinolones [21], i.e., flumequine and nalidixic acid, using NTO under solar light passed through fourteen stable 
intermediates that were identified using liquid chromatography-time of flight-mass spectrometry. In another example, five hydroxylated intermediates (Scheme 1a) were identified in the degradation of a pesticide, carbofuran [22]. The role of $\cdot \mathrm{OH}$ in the initiation of this photocatalytic degradation was confirmed by the knowledge of carbofuran adsorption on P25 catalyst and by conduction of the experiments using a non-aqueous solvent, acetonitrile. Carbofuran showed a negligible adsorption $(\sim 1 \%)$ on Degussa P25 $\mathrm{TiO}_{2}$ catalyst. The absence of adsorption eliminates the possibility of the direct oxidation of carbofuran by surface-generated holes [22], which is considered to be a minor secondary reaction in NTO photocatalytic degradation [25,26] on $\mathrm{TiO}_{2}$ catalysts under UV illumination. When this experiment was conducted in the non-aqueous solvent, acetonitrile, total inhibition of carbofuran degradation was observed [22], due to the low production of $\cdot \mathrm{OH}$ in acetonitrile. These findings show that the photocatalytic degradation of aqueous pollutants is initiated mainly by $\cdot \mathrm{OH}$ attack. However, An et al. reported [25] secondary mechanistic pathways for the photocatalytic degradation of the antivirus drug lamivudine by UV-irradiated NTO. These secondary pathways originated from photogenerated holes on NTO, which caused the initial oxidation of the lamivudine adsorbed on the NTO surface (Scheme 1b). It is important to note that these secondary degradation pathways initiated by photogenerated holes were minor side reactions; the major degradation pathway of lamivudine was through $\cdot \mathrm{OH}$ attack.

Table 1. Recent examples of pollutants photocatalytically degraded by NTO.

\begin{tabular}{|c|c|c|}
\hline Contaminant & Photocatalytic system & Ref. \\
\hline \multicolumn{3}{|l|}{ Dyes } \\
\hline Reactive violet 5 & UV/Anatase powder (Sigma Aldrich) & {$[27]$} \\
\hline Blue 9, Red 51\& Yellow 23 & Solar/TiO 2 (Degussa P25) & {$[28]$} \\
\hline Methyl orange & $\mathrm{UV} / \mathrm{TiO}_{2}$ on glass & [29] \\
\hline Methylene blue & $\mathrm{UV} / \mathrm{TiO}_{2}($ Merck) on volcanic ash & {$[30]$} \\
\hline Rhodamine B & $\mathrm{UV} / \mathrm{TiO}_{2}$ bilayer & {$[31]$} \\
\hline \multicolumn{3}{|l|}{ Pesticides \& herbicides } \\
\hline $\begin{array}{l}\text { Organophosphate \& } \\
\text { Phosphonoglycine }\end{array}$ & $\mathrm{UV} / \mathrm{TiO}_{2}$ immobilized on silica gel & {$[32]$} \\
\hline Azimsulfuron & $\mathrm{UV} / \mathrm{TiO}_{2}$ coated on glass rings & {$[33]$} \\
\hline Swep residues & Simulated sunlight/ $/ \mathrm{TiO}_{2}($ Degussa P25) & [34] \\
\hline Pharmaceuticals \& cosmetics & $\begin{array}{l}\text { Electrocoagulation \& } \mathrm{UV} / \mathrm{TiO}_{2} / \mathrm{H}_{2} \mathrm{O}_{2} \\
\mathrm{UV} / \mathrm{TiO}_{2} \text { (Aeroxide } \mathrm{P} 25 \text { ) } \\
\mathrm{TiO}_{2} / \mathrm{Fe}_{3} \mathrm{O}_{4} \& \mathrm{TiO}_{2} / \mathrm{SiO}_{2} / \mathrm{Fe}_{3} \mathrm{O}_{4}\end{array}$ & $\begin{array}{l}{[35]} \\
{[9,10,36]} \\
{[37]}\end{array}$ \\
\hline $\begin{array}{l}\text { Benzylparaben } \\
\text { Drugs }\end{array}$ & $\mathrm{UV} / \mathrm{TiO}_{2}($ Degussa P25) & {$[38]$} \\
\hline Oxolinic acid & $\mathrm{UV} / \mathrm{TiO}_{2}($ Degussa P25) & {$[39]$} \\
\hline \multirow{2}{*}{ Atenolol \& propranolol } & UV/Commercial $\mathrm{TiO}_{2} \mathrm{~S}$ & {$[40]$} \\
\hline & Solar/TiO ${ }_{2}$ (six commercial samples $) / \mathrm{H}_{2} \mathrm{O}_{2}$ & [41] \\
\hline \multirow{2}{*}{$\begin{array}{l}\text { Ciprofloxacin, ofloxacin, } \\
\text { norfloxacin \& enrofloxacin }\end{array}$} & $\mathrm{UV}^{\mathrm{TiO}} \mathrm{T}_{2}($ Degussa P25) & {$[42]$} \\
\hline & Simulated solar/ $/ \mathrm{TiO}_{2} \mathrm{P} 25$ & {$[43]$} \\
\hline Lamivudine & UV/TiO 2 (Degussa P25) & {$[25]$} \\
\hline Oxytetracycline & $\mathrm{UV} / \mathrm{TiO}_{2}$ (Degussa P25) & [44] \\
\hline
\end{tabular}


Table 1. Cont.

\begin{tabular}{|c|c|c|}
\hline \multicolumn{3}{|l|}{ Others } \\
\hline $\begin{array}{l}N, N \text {-diethyl- } m \text {-toluamide } \\
\text { (Insect repellent) }\end{array}$ & $\mathrm{UV} / \mathrm{TiO}_{2}($ Degussa P25) & {$[20,45]$} \\
\hline$\beta$-naphthol & $\mathrm{UV} / \mathrm{TiO}_{2}-\mathrm{SiO}_{2}$ & {$[46]$} \\
\hline 15 emerging contaminants & Solar $\mathrm{UV} / \mathrm{TiO}_{2}$ coated on glass spheres & [47] \\
\hline Grey water & $\mathrm{UV} / \mathrm{TiO}_{2}($ Aeroxide $\mathrm{P} 25)$ & {$[12]$} \\
\hline \multirow[t]{3}{*}{ Microcystins (Cyanotoxin) } & $\mathrm{UV} / \mathrm{TiO}_{2}$ film & {$[48,49]$} \\
\hline & UV/Doped $\mathrm{TiO}_{2}$ & {$[50]$} \\
\hline & UV/ Nitrogen doped $\mathrm{TiO}_{2}$ & [51] \\
\hline Lipid vesicles \& E. coli cells & $\mathrm{UV} / \mathrm{TiO}_{2}($ Degussa P25) & {$[52]$} \\
\hline \multirow[t]{2}{*}{ Bacterial colony } & $\mathrm{UV} / \mathrm{TiO}_{2}$ on titanium beads & {$[53]$} \\
\hline & $\mathrm{UV} / \mathrm{TiO}_{2}$-coated bio-film & {$[54]$} \\
\hline Paper mill wastewater & Solar/ $/ \mathrm{TiO}_{2}$ & {$[11]$} \\
\hline Endocrine disrupting compounds & $\mathrm{UV} / \mathrm{TiO}_{2}($ Degussa P25) & {$[55]$} \\
\hline Municipal waste water & Solar/sol-gel $\mathrm{TiO}_{2} \&$ Degussa P25 & {$[13]$} \\
\hline Contaminated soil & $\mathrm{Plasma} \mathrm{TiO}_{2}(($ Degussa P25) & {$[56]$} \\
\hline
\end{tabular}

Figure 2. Photocatalytic generation of hydroxyl radicals.

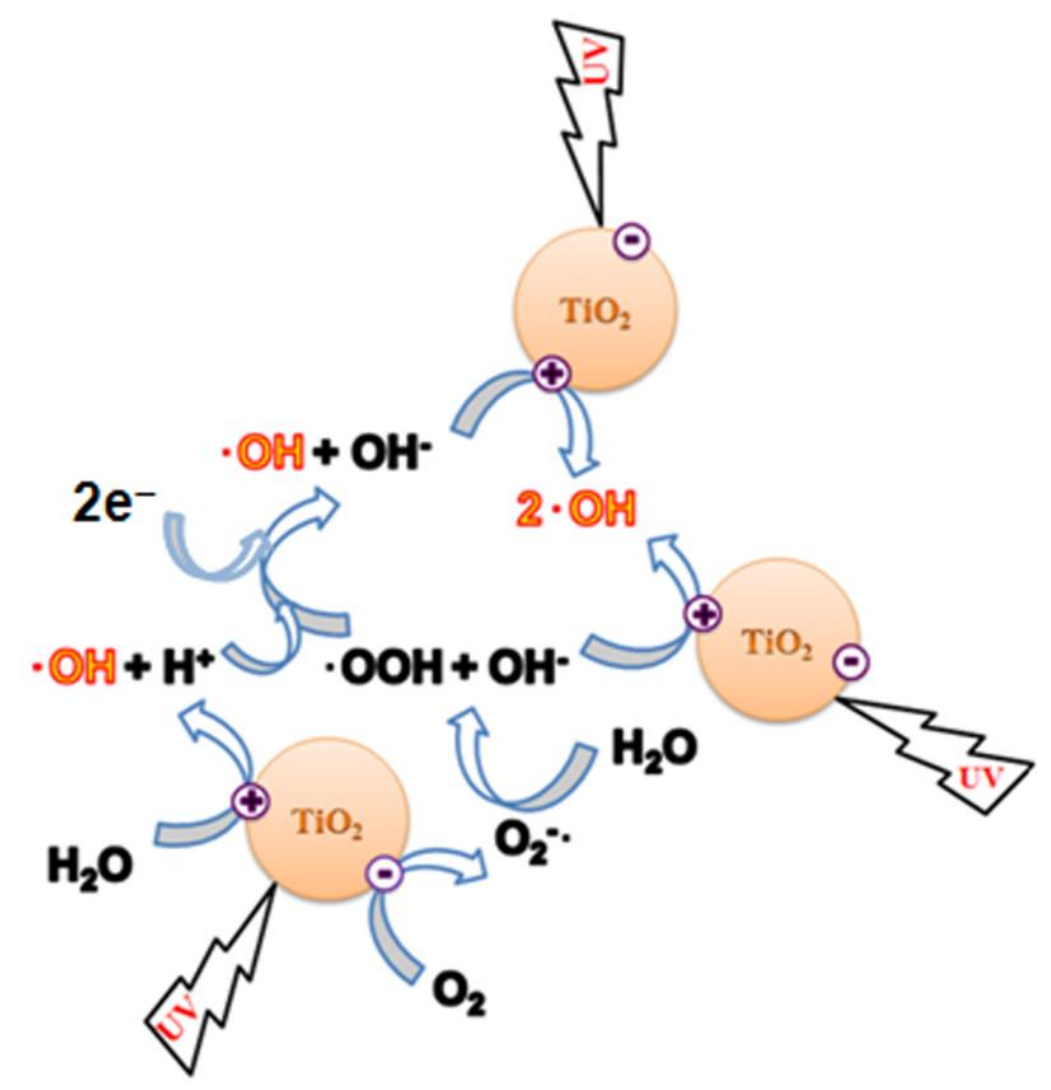


Scheme 1. Photocatalytic degradation pathways of (a) carbofuran and (b) lamivudine (Reproduced from [22] and [25] respectively, copyright (2011), with permission from Elsevier).

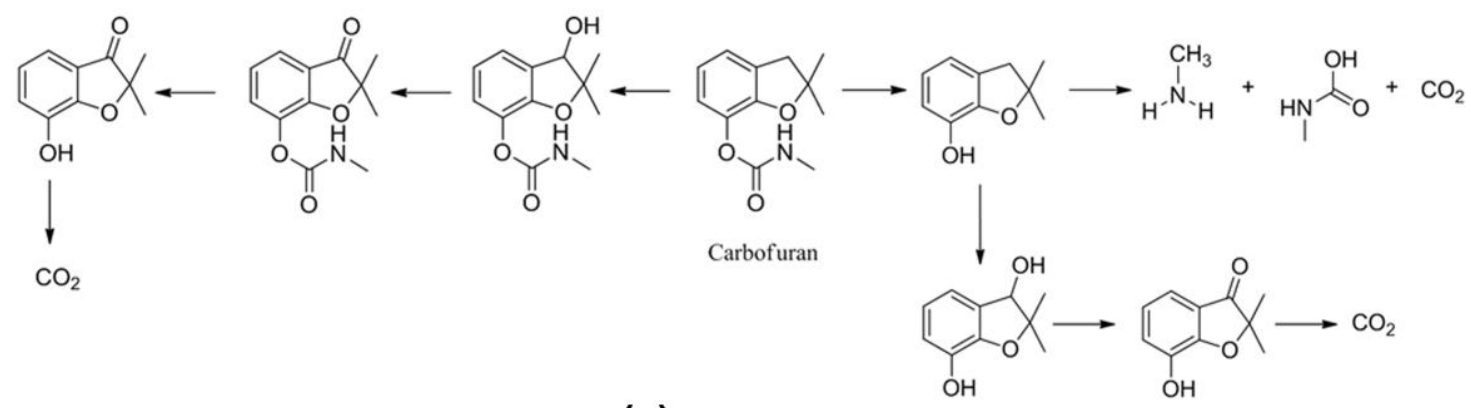

(a)

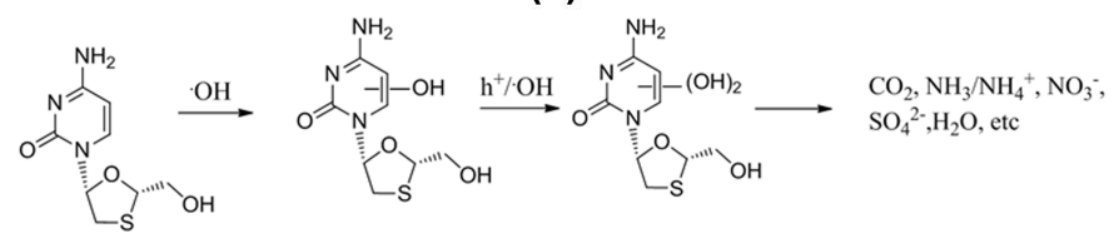

Lamivudine

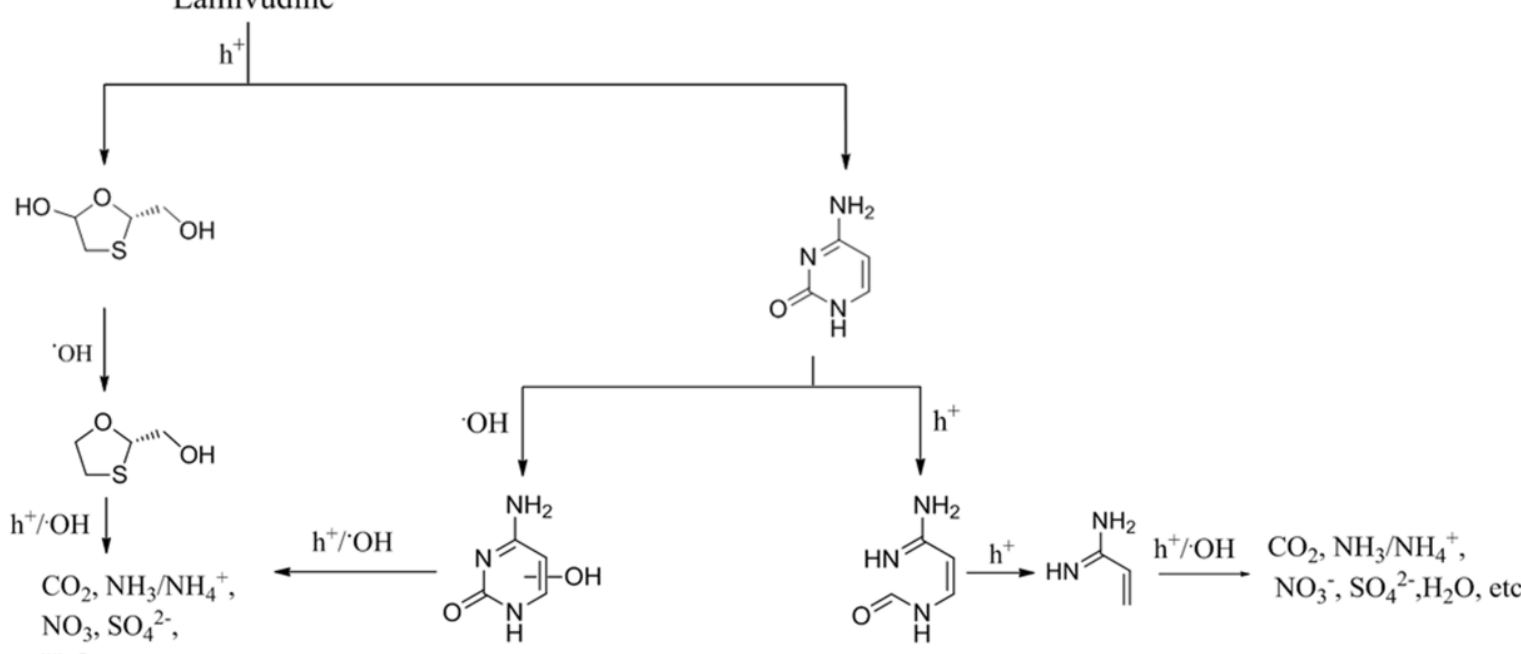

(b)

The kinetics of the photocatalytic degradation of aqueous pollutants by NTO is still a subject of debate [57-59]. Several recent reports claim that it follows the Langmuir-Hinshelwood model (L-H model) of kinetics $[21,22,25,26]$. However, the validity of $\mathrm{L}-\mathrm{H}$ model in photocatalytic degradation reactions could be a misconception or rather an easier way of interpretation [60]. Therefore reporting L-H model of kinetics in photocatalytic degradation without proper experimental evidences is dubious. The kinetic profile for the degradation of methylparaben, a bactericide and antimicrobial agent in personal care products, by NTO photocatalysis has been reported to follow the L-H model, where the rate expression can be shown as follows [26].

$$
r=-\frac{d C}{d t}=k_{L H} \theta=k_{L H} \frac{K_{L} C_{\mathrm{eq}}}{1+K_{L} C_{\mathrm{eq}}}
$$

where $r$ is the reaction rate, $k_{\mathrm{LH}}$ is the apparent $\mathrm{L}-\mathrm{H}$ rate constant, $\theta$ is the surface coverage of methylparaben, $K_{\mathrm{L}}$ is the Langmuir adsorption constant, and $C_{e q}$ is the equilibrium concentration. At 
low concentrations of methylparaben, $K_{\mathrm{L}} C_{e q}\left(K_{\mathrm{L}} C_{e q}<<1\right)$ is negligible and Equation (1) becomes a pseudo-first-order rate expression [26], as denoted below.

$$
r=-\frac{d C}{d t}=k_{L H} K_{L} C_{e q}=k_{a p p} C_{e q}
$$

Integrating Equation (2)

$$
\ln \frac{C_{a q}}{C}=k_{a p p} t+\text { constant }
$$

Equations (1)-(3) account for the adsorption of the reactant (methylparaben) only but do not consider the adsorption on NTO of any intermediates or products formed during the course of the degradation reaction. When the adsorption of intermediates or products must be considered [21], a modified rate equation results, as shown below.

$$
r=-\frac{d C}{d t}=k_{L H} \frac{K_{L} C_{e q}}{1+K_{L} C_{e q}+\sum_{i=1}^{n} K_{i} C_{i}(i=1, n)}
$$

where $K_{i}$ and $C_{i}$ are the adsorption constant and concentration of intermediates at any given time, respectively. When the initial concentration of pollutants is very low, $1+K_{\mathrm{L}} C_{e q}+\sum_{i=1}^{n}$ is negligible and the reaction follows pseudo-first-order kinetics, as shown in Equations (2) and (3).

Sirtori et al. have reported that the photocatalytic degradation by NTO follows L-H kinetics at low pollutant concentrations and below the catalyst saturation level [21]. It deviates from the pseudo-first-order kinetics under several conditions. The NTO catalyst concentration and the light flux have been found to influence the degradation kinetics of methylparaben [26]. According to the L-H model, the photocatalytic degradation rate of methylparaben should increase with an increase in the NTO catalyst loading because of the additional available active sites $(\theta)$ for adsorption. This was observed up to a certain catalyst loading (catalyst saturation), but above that limit, the experimental kinetics results did not fit the L-H model [26]. This was mainly ascribed to three reasons: at higher NTO loading, (i) deactivation of activated NTO could occur upon collision with ground state NTO catalysts, (ii) there is a higher possibility of agglomeration and sedimentation of NTO, and (iii) there is decreased light penetration through the reaction medium. UV light flux has been found to be an important influence on the degradation kinetics of methylparaben in aqueous medium [26]. At low UV light flux $\left(1.2 \times 10^{15}\right.$ photons s $\mathrm{cm}^{-1}<\Phi<4.0 \times 10^{15}$ photons s $\mathrm{cm}^{-1}$ ), methylparaben degradation followed L-H kinetics, where electron-hole pairs mainly resulted in chemical reactions rather than recombination. However, at intermediate UV light intensities $\left(4.0 \times 10^{15}\right.$ photons s${ }^{-1} \mathrm{~cm}^{-2}<\Phi<5.8 \times 10^{15}$ photons s $\left.\mathrm{cm}^{-2}\right)$, the methylparaben degradation rate varied as a functional order between zero and one. In this medium UV light region, the recombination of electron-hole pairs was predominant over degradation. The random selection of a particular concentration of the pollutant is not enough to study the dependence of rate on photon flow [60]. Concentration of the pollutant is also important as demonstrated by Serpone et al. [60] where the order of the photocatalytic reaction varied between zero (at low pollutant concentration) and one (at high pollutant concentration) in the same range of light irradiance. Therefore a complete study should focus on different concentrations of pollutant to know the dependence of light irradiance on the photocatalytic reaction rate. 
Wang et al. posited a rate expression that was different from the conventional pseudo-first-order rate equation, to explain the kinetics of sulfosalicylic acid degradation in aqueous solution using NTO [57]. Their proposed rate equation considers factors such as the lifetime and concentration of $\cdot \mathrm{OH}, \mathrm{pH}$, and adsorption of intermediates on NTO. The rate equation can be represented as follows.

$$
\begin{gathered}
-\frac{d C}{d t}=\frac{k_{+3} k_{4} \tau\left[h^{+}\right]}{k_{-3}\left[H^{+}\right]} \frac{K_{a} C_{e q}}{1+\sum_{i=5}^{n} K_{i} C_{i}+K_{a} C_{e q}} \\
\frac{k_{+3}\left[h^{+}\right]}{k_{-3}\left[H^{+}\right]}=\left[{ }^{\circ} \mathrm{OH}\right]
\end{gathered}
$$

where, $\tau$ is the lifetime of $\cdot \mathrm{OH}$ and $k_{4}$ is the rate constant for the reaction of $\cdot \mathrm{OH}$ with the adsorbed pollutant on NTO. $K_{Q}$ and $K i$ are the adsorption equilibrium constants of sulfosalicylic acid and the intermediates, respectively, and $C_{e q}$ and $C_{i}$ are their equilibrium concentrations. Adsorption of the identified intermediates of sulfosalicylic acid degradation on NTO was found to be insignificant [57]; hence, Equation (5) can be simplified as

$$
-\frac{d C}{d t}=\frac{k_{+3} k_{4} \tau\left[h^{+}\right]}{k_{-3}\left[H^{+}\right]} \frac{K_{a} C_{e q}}{1+K_{a} C_{\varepsilon \sigma}}
$$

Integrating Equation (7), we get

$$
\begin{gathered}
\ln \left(\frac{C_{e q}}{C}\right)+K_{a}\left(C_{e q}-c\right)=k_{a p p} t \\
k_{a p p}=\frac{k_{+3} k_{4} \tau\left[h^{+}\right]}{k_{-3}\left[H^{+}\right]} K_{a}
\end{gathered}
$$

The order of the degradation reaction will then be determined by three different adsorption situations: (i) weak adsorption $\left(K_{Q} C_{e q}<1\right)$; (ii) medium adsorption $\left(0.1<K_{Q} C_{e q}<10\right)$, and (iii) strong adsorption $\left(K_{Q} C_{e q}>10\right)$ [57]. In the case of weak adsorption of the pollutant on NTO, Equation (8) reduces to the pseudo-first-order expression, as shown in Equation (3). Medium adsorption leads to Equation (8), which was observed in the case of sulfosalicylic acid degradation kinetics. In the case of strong adsorption, the rate is independent of $K_{Q}$ and adsorption does not affect the rate of the reaction; here, the reaction will follow a zero-order kinetic model and the rate expression becomes

$$
\ln \left(\frac{C_{e q}}{C}\right)=k_{\text {ayp }}
$$

Pace of photocatalytic degradation of a particular pollutant also depends on other factors such as alkalinity, and the presence of natural organic matter, [61] especially in real systems. Carbonate and bicarbonate ions, which are responsible for the alkalinity of water, have been found to decrease the rate of the photocatalytic degradation of microcystine-LR [61]. Also, the presence of humic acid and fulvic acid (natural organic matter) reduced the rate of microcystine-LR degradation [61]. 


\section{Activity Enhancement}

Recent efforts to enhance the photocatalytic activity of NTO include the synthesis of mesoporous $\mathrm{TiO}_{2}$ [62-72], the use of different $\mathrm{TiO}_{2}$ morphologies (nanowires, nanotubes, and nanospheres) [73-76], reducing the agglomeration in NTO powders [77-79], and surface treatments of NTO [80-83]. Synthesis of mesoporous NTO is a means to achieve $\mathrm{TiO}_{2}$ photocatalysts with improved photocatalytic activities. Some of the recently reported mesoporous $\mathrm{TiO}_{2}$ photocatalysts exhibited superior photocatalytic activity than the bench mark Degussa $\mathrm{P} 25 \mathrm{TiO}_{2}$ photocatalyst. $\mathrm{TiO}_{2}$ photocatalysts with active $\{001\}$ facets were derived hydrothermally by using ammonium fluoride [62] or mild sulfuric acid [63] capping agents and showed superior dye degradation activity in comparison with the Degussa P25. Mesoporous $\mathrm{TiO}_{2}$ catalysts synthesized by using F127 triblock copolymer [64], polystyrene [65], and silica [66] (through etching and recalcination method) have been reported for the efficient degradation of methanol, methyl orange and rhodamine B pollutants, respectively. These synthesized mesoporous catalysts outperformed the commercially available Degussa P25 and Hombicat UV-100 [64] photocatalyts in their photocatalytic activity.

NTO nanowires obtained by the post-calcination of hydrothermally derived titanates were found to be more efficient than Degussa P25 in the degradation of humic acid [73] and Reactive Brilliant Blue $\mathrm{X}-\mathrm{BR}$ [75]. These nanowires also caused less serious fouling than P25 in microfiltration membranes. In another study [74], NTO nanotubes obtained by the anodic oxidation of titanium metal plate were 25-40\% more efficient than the nanoparticle-based experimental system for the degradation of rhodamine B. Anatase submicrospheres consisting of NTO nanorods (20-30 nm in diameter) with thorn-like shells have been reported [76]. This morphology resulted in multiple reflections of the incident light, and the catalyst was found to be equally comparable with P25 in the degradation of methylene blue dye solution under UV irradiation.

The agglomeration of NTO during its formation can reduce the dispersion of $\mathrm{TiO}_{2}$ in aqueous suspensions, contributing to decreased photocatalytic activity. The agglomeration of $\mathrm{TiO}_{2}$ can be minimized by changing the $\mathrm{pH}$ of the reaction mixture [78], adsorbing polyallylamine hydrochloride on the $\mathrm{TiO}_{2}$ surface [78], adopting a flame hydrolysis synthesis route [79], or ball milling of the $\mathrm{TiO}_{2}$ powder [77]. All attempts were successful in reducing the agglomeration of NTO in aqueous suspensions, but the photocatalytic activities were found to depend not only on agglomeration but also on several other factors. Recently reported surface treatments include surface fluorination [81], high-energy electron beam treatment [82], modification with S-1-dodecyl-S'-( $\alpha, \alpha^{\prime}$-dimethyl- $\alpha$ "-acetic acid) trithiocarbonate (DDAT) [83], and incorporation of a $\mathrm{TiO}_{2}$ microsphere layer [80]. During the photooxidation of catechol and phenol, an electrochemical surface-fluorinated NTO electrode could reduce electron-hole recombination and also displace the oxidizable organic compounds and poisoning species from the surface [81]. This resulted in the superior performance of the fluorinated $\mathrm{TiO}_{2}$ versus the bare $\mathrm{TiO}_{2}$ electrode. In the high-energy electron beam treatment of NTO, the carbon content on the $\mathrm{TiO}_{2}$ surface was increased by the burning of impurities already present on the catalyst [82]. This increased the hydrophilicity and the photocatalytic activity of the electron beam-treated $\mathrm{TiO}_{2}$ in the degradation of methylene blue dye. Modifying NTO with DDAT caused a red shift in the absorbance of the modified catalyst through a ligand-to-metal charge transfer transition, which enhanced its visible light activity towards the degradation of 2,4-dichlorophenol, when compared to the as-prepared $\mathrm{TiO}_{2}$ 
catalyst [83]. The formation of a $\mathrm{TiO}_{2}$ microsphere layer over a nanostructured $\mathrm{TiO}_{2}$ layer (deposited on Pyrex glass by spin coating) increased the contact area for methylene blue dye in aqueous solution, resulting in faster degradation kinetics [80].

\section{Immobilization of $\mathrm{TiO}_{2}$}

Immobilization of $\mathrm{TiO}_{2}$ on various substrates is an important research area with its photocatalytic water treatment applications [84]. The primary aim of doing so is to avoid the post separation difficulties associated with the powder form of the $\mathrm{TiO}_{2}$ catalyst. However, there are several other advantages including higher surface area, superior adsorption properties [30,85,86], and increased surface hydroxyl groups or reduced charge recombination [87] are achievable in immobilized systems. Immobilization of $\mathrm{TiO}_{2}$ can be done on powder/pellet substrates $[30,85,86]$, soft/thin materials [54,88-93] or on rigid/thick substrates. Some of the recent examples of powder/pellet substrates include activated carbon [85], vermiculite (magnesium-aluminium silicates) [86], and volcanic ash [30]. Sedimentation of these $\mathrm{TiO}_{2}$ immobilized systems could be easier than the $\mathrm{TiO}_{2}$ catalyst alone systems, since they are heavier particles. $\mathrm{TiO}_{2}$ immobilized on soft/thin substrates, normally referred as $\mathrm{TiO}_{2}$ membrane or films, are applicable in ultra filtration and bacterial inactivation. Since they are immobilized with $\mathrm{TiO}_{2}$, they can act as self cleaning surfaces. Recent examples of this category include $\mathrm{TiO}_{2}$ immobilized on alumina (1.5 micron thick) [88-90], polyvinylidene difluoride [91], glass filter [92], cellulose fibres [93], and sponge [54]. Various immobilization techniques such as chemical vapour deposition [89,90], slip coating [88], dip coating [88], film casting [91], electrospinning [92,93] and dip-evaporation [54] has been employed to achieve the immobilization of $\mathrm{TiO}_{2}$ on soft/thin substrates.

Immobilization of $\mathrm{TiO}_{2}$ on rigid substrates is mostly done on glass [31,33,87,94-98]. Main advantage with glass substrate is the transparency of the system even after the immobilization. This can allow the penetration of light which can result in improved photocatalysis. Dionysiou et al. [94] have reported a non-ionic surfactant (Tween20) templated self assembly pathway to immobilize $\mathrm{TiO}_{2}$ on borosilicate glass by the dip coating technique. The use of surfactant resulted in a uniform and crack free $\mathrm{TiO}_{2}$ surface with partially ordered mesoporosity to the calcined borosilicate glass $\mathrm{TiO}_{2}$ films. Addition of Degussa P25 to the surfactant containing $\mathrm{TiO}_{2}$ sol imparted a bimodal mesoporous structure to the catalyst immobilized system which improved the structural integrity of the films [95]. The use of a non-ionic fluoro surfactant (Zonyl FS-300) instead of Tween 20, and the addition of ethylene diamine into the $\mathrm{TiO}_{2}$ sol for dip coating; nitrogen and fluorine co-doped visible light active $\mathrm{TiO}_{2}$ coating on borosilicate glass was achieved (after calcination) [96]. Interestingly, the surface was found to be hydrophilic under both UV and visible (400-510 nm) light exposure while the undoped $\mathrm{TiO}_{2}$ surface was hydrophilic only under UV light [97]. They could also achieve sulfur doped visible light active (after calcination) $\mathrm{TiO}_{2}$ coating by adding sulfuric acid (sulfur precursor) and polyoxyethylene (80) sorbitan monooleate surfactant (as pore directing agent) into the $\mathrm{TiO}_{2}$ sol [98]. All these $\mathrm{TiO}_{2}$ immobilized borosilicate glass systems were successfully tested for the photocatalytic degradation of creatinine [94,95], microcystines [96,98-100], and cylindrospermopsin [100] under UV/visible light irradiation. 
The role of surface defects in the $\mathrm{TiO}_{2}$ surface on the photocatalytic degradation mechanism is demonstrated by Zhuang et al [31]. They produced three $\mathrm{TiO}_{2}$ immobilized systems (with normal surface, surface defects and with interface defects) on quartz by either using dip coating techniques alone or using both dip coating and cold plasma treatment techniques. The normal $\mathrm{TiO}_{2}$ surface mainly promoted $\mathrm{N}$-deethylation of rhodamine $\mathrm{B}(\mathrm{Rh} \mathrm{B})$ dye while the $\mathrm{TiO}_{2}$ surface with defects was very efficient for cycloreversion of $\mathrm{RhB}$. The $\mathrm{TiO}_{2}$ surface with interface defects showed both mechanisms and was found to be the best system for the Rh B dye degradation.

\section{Photocatalytic Reactors}

Reactor design is an intense focus for photocatalytic water treatment. Here, reviewed photocatalytic reactors can be divided in to two categories, i.e., (i) lab-scale reactors [74,101-111], where the volume of reactant solution is $<1 \mathrm{~L}$, and (ii) pilot plant-scale reactors [44,112-116], where the reactor volume is $>5 \mathrm{~L}$. Recent innovations in lab-scale reactors include the use of energy-efficient UV/visible light emitting diodes (LEDs) as light sources [101-105], the design of rotating disc-type reactor models [74,106], the fabrication of NTO-immobilized catalytic beds [107,108], and post-separation/reuse of NTO powder catalysts [109-111]. LEDs are light sources that need less energy and, therefore, LED-based photocatalytic reactors are more energy-efficient systems. The combination of UV-LEDs and NTO powder [101], NTO nanotubes [102], or immobilized NTO [103,104] has been reported for the degradation of various dyes such as methyl orange, methylene blue, rhodamine $\mathrm{B}$, and malachite green. The UV-LED photoreactor developed by Nickels et al. [104] was equipped with a microcirculating fluid pump (to keep the reactant solution constantly mixed) and an in-stream sensor unit (Figure 3). The sensor unit, an assembly of a liquid flow cell with transparent windows, an LED lamp, and a photodiode monitor, enabled the real-time evaluation of the decrease in the concentration of methyl orange dye. Other attributes of the reactor, such as its light weight, low production cost, and flexibility, make this design ideal for both laboratory and field work applications, as claimed by the authors. Visible LEDs with carbon-nitrogen co-doped NTO achieved the visible light degradation of bisphenol [105]. The reactor consisted of four strips of visible LEDs, i.e., white, green, blue, and yellow, which covered the wavelength range of 450 to $600 \mathrm{~nm}$.

Rotating disc reactor design in NTO photocatalysis has several merits as first demonstrated by Dionysiou et al. $[117,118]$. A NTO-coated borosilicate rotating disc (diameter $=6 \mathrm{~cm}$ ) was reported for the degradation of methyl orange dye [106]. The aqueous methyl orange solution film thickness on the disc was optimized by adjusting the flow rate of the reactant feed and the rotating speed of the disc. Zhang et al. designed a rotating disc reactor of $\mathrm{TiO}_{2}$ nanotubes by the anodization of a Ti metal plate [74]. Half of the disc was always immersed in the bulk solution of the reactant rhodamine B dye, whereas the other half was exposed to air. They observed a faster degradation rate for rhodamine B dye on the air-exposed disc surface than in the bulk of the solution. This $\mathrm{TiO}_{2}$ nanotube disc reactor was $20-25 \%$ more efficient than the $\mathrm{TiO}_{2}$ nanoparticle-coated disc system. 
Figure 3. Schematic of the UV-LED-based photocatalytic reactor equipped with a real time in-stream sensor unit (Adapted with permission from [104]. Copyright (2012) American Chemical Society).

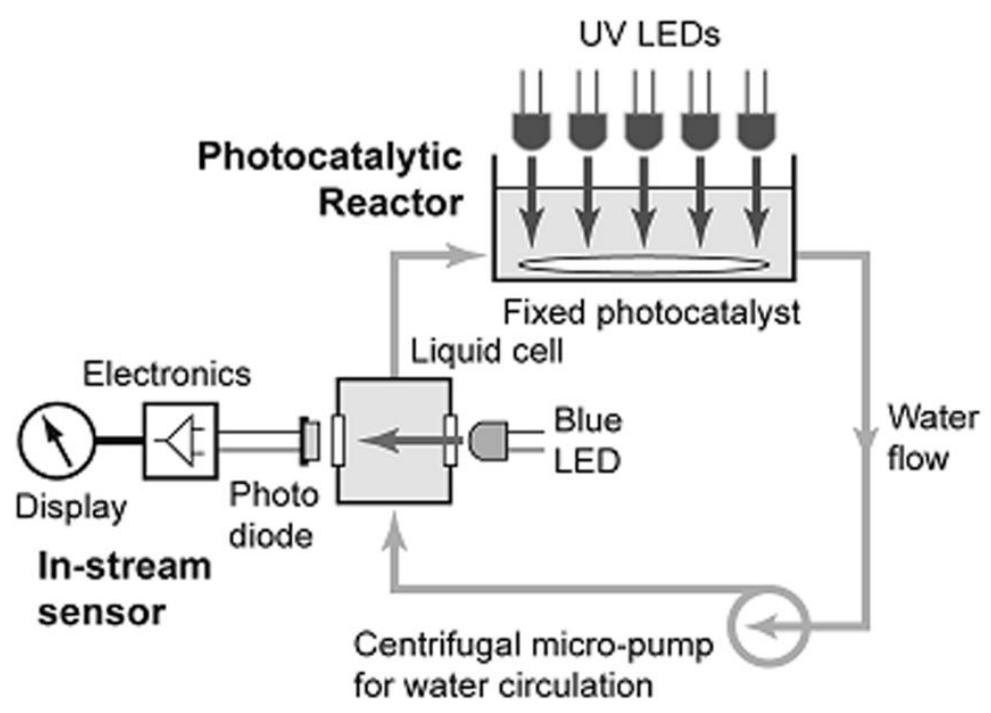

Recently reported immobilized catalytic bed designs include a NTO-coated pebble bed photocatalytic reactor [107] and an ETS-10 (Engelhard titanosilicate structure 10)-coated optic fiber reactor [108]. The former consisted of a Perplex ${ }^{\mathrm{TM}}$ sheet onto which NTO-coated pebbles were affixed [107]. The arrangement of the pebbles was such that the pebbles in one row formed an equilateral triangle with the pebbles in the next row. Keeping the reactor in a horizontal position, textile dye solution $(0.66 \mathrm{~L})$ was degraded under sunlight irradiation. In the other example, the ETS-10-coated optic fiber reactor showed 4-5 times greater quantum efficiency than an ETS-10 slurry reactor in degrading methylene blue dye solution under UV light illumination [108]. The reactor consisted of optical fibers, uniformly coated with ETS-10, inserted in an acrylic cylinder.

Post separation of NTO powder catalysts in slurry reactors is one of the major challenges in photocatalytic water treatment. Toward this end, Kim et al. [109] reported a reactor design in which the P25 powder catalyst could be separated from the treated water by a submerged microfiltration membrane. They used this reactor system in conjunction with reverse osmosis for the photocatalytic treatment of seawater samples. In another reactor design, Suryaman et al. [110] achieved the natural sedimentation of the P25 powder catalyst after phenol degradation in pipe water. Treated water overflowed from the separation tank, whereas the P25 catalyst settled at the bottom of the separation tank. The use of NTO pellets is another option to avoid post separation requirements in photocatalytic reactors. With a patented "drum reactor" design [111], McCullagh et al. reported the degradation of methylene blue dye solution by Hombikat $\mathrm{TiO}_{2}$ pellets. The reactor had three cylinders with paddles, which contained $\mathrm{TiO}_{2}$ pellets. Each cylinder was supplied with $36 \mathrm{~W}$ UV lamps and was connected to a $12 \mathrm{~V}$ motor to effect cylinder rotation.

Recently reported pilot plant photocatalytic reactors have mainly utilized natural sunlight as a light source $[44,112,113,115,116]$. However, an UV light-based pilot plant reactor has also been reported [114]. The use of NTO in powder $[44,112,114,116]$ or immobilized forms $[113,115]$ has also been examined. 
Table 2 depicts some recent examples of pilot plant photocatalytic reactors used for the degradation of various contaminants.

Table 2. Examples of large-scale photocatalytic reactors.

\begin{tabular}{|c|c|c|c|c|}
\hline Reactor type & $\begin{array}{l}\text { Experimental } \\
\text { condition }\end{array}$ & $\begin{array}{l}\text { Volume } \\
\text { (L) }\end{array}$ & pollutant & Ref. \\
\hline $\begin{array}{l}\text { Compound parabolic } \\
\text { collector pilot-plant }\end{array}$ & $0.2 \mathrm{~g} \mathrm{~L}^{-1} /$ solar & $\begin{array}{ll}22 & \& \\
110 & \end{array}$ & $\begin{array}{l}\text { Cork boiling and } \\
\text { bleaching waste } \\
\text { water }\end{array}$ & [112] \\
\hline $\begin{array}{l}\text { Concentric parabolic } \\
\text { concentrator pilot-plant }\end{array}$ & $\begin{array}{l}\mathrm{TiO}_{2} \text { coated paper } \\
\left(20 \mathrm{~g} \mathrm{~m}^{-2}\right) / \text { solar }\end{array}$ & 16.2 & Humic substances & [113] \\
\hline Membrane pilot system & $0.05 \mathrm{~g} \mathrm{~L}^{-1} / \mathrm{UV}$ & - & 32 pharmaceuticals & [114] \\
\hline $\begin{array}{l}\text { Thin film fixed-bed } \\
\text { reactor }\end{array}$ & $\begin{array}{l}\mathrm{TiO}_{2} \text { on the } \\
\text { reactor walls/solar }\end{array}$ & - & $\begin{array}{l}\text { Yellow Cibacron } \\
\text { FN-2R }\end{array}$ & [115] \\
\hline $\begin{array}{l}\text { Tubular continuous flow } \\
\text { pilot-plant }\end{array}$ & $0.1 \mathrm{~g} \mathrm{~L}^{-1} /$ solar & 7 & $\begin{array}{l}\text { p-nitrophenol, } \\
\text { naphthalene, } \\
\text { dibenzothiophene }\end{array}$ & [116] \\
\hline $\begin{array}{l}\text { Compound parabolic } \\
\text { collector pilot-plant }\end{array}$ & $0.5 \mathrm{~g} \mathrm{~L}^{-1} /$ solar & 6 & Oxytetracyclin & [44] \\
\hline
\end{tabular}

\section{Doping}

The band gaps (3-3.2 eV) of NTO semiconductors, which absorb from the UV region of the solar spectrum, are drawbacks in photocatalysis; only about 5\% of sunlight comprises UV radiation. Modification of the band gap in NTO is, therefore, a well-studied research area. Modifications can be effected either in bulk or on the surface of $\mathrm{TiO}_{2}$ (Scheme 2). Surface modifications are usually achieved by anchoring colored inorganic semiconductors (for example, CdS and CdSe) [119] or organic dyes on the $\mathrm{TiO}_{2}$ surface [120], where they act as sensitizers. However, most of these sensitizers are susceptible to photocorrosion or degradation in aqueous solutions and are not suitable for photocatalytic water-treatment applications. Instead, they are good candidates for solar cell devices. On the other hand, bulk modification is mainly effected by doping metals or non-metals into bulk NTO. The modified catalysts appear to be photo-stable in aqueous solution and can be used in photocatalytic water purification.

Scheme 2. Different methods of modification on NTO.

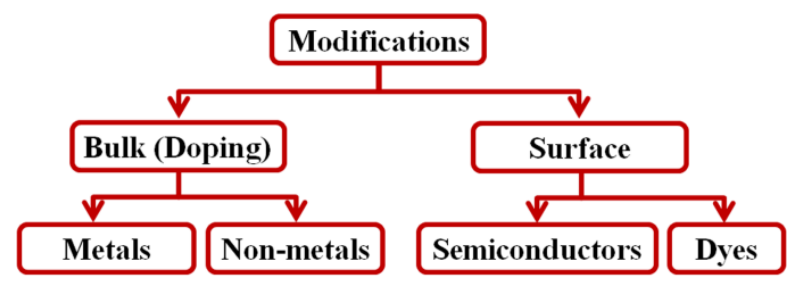


Figure 4. Creation of additional bands in NTO by doping.

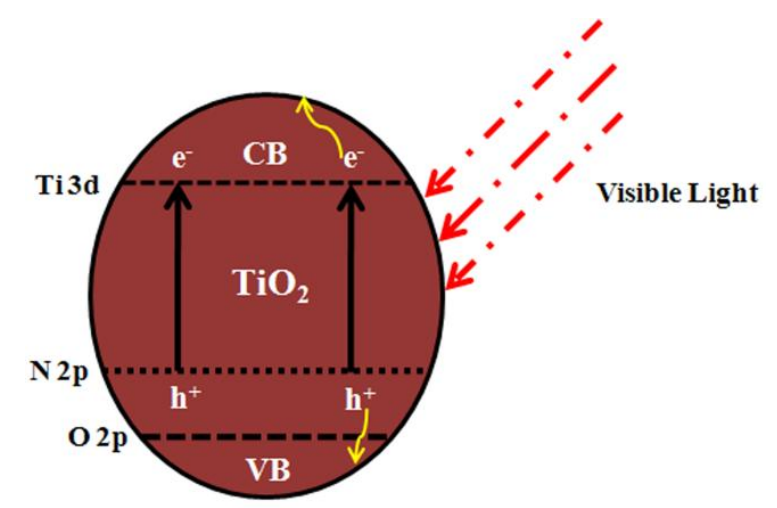

Doping NTO with metals and non-metals creates new energy levels between the VB and CB of $\mathrm{TiO}_{2}$ [121], which in turn reduces its band gap and helps the doped catalyst to absorb in the visible region (Figure 4). Recently, researchers have reported the successful doping of vanadium [122], iron [123], rhodium [50], palladium [124], and silver [125] metals, and carbon [105,126], nitrogen [51,96,105,121,124,127,128], sulfur [98,129], fluorine [96], and iodine [130] non-metals in NTO to achieve the visible light photocatalytic degradation of various chemicals and Escherichia coli in aqueous solution (Table 3). In all reports, except in silver doping, the visible light photocatalytic activity was mainly attributed to the associated red shift that originated from the creation of local bands between the VB and CB of NTO (Figure 4). Silver doping in P25 by a photoreduction method did not reduce the band gap of the doped catalyst, but superior photocatalytic degradation of oxalic acid was still observed, when compared to un-doped P25, under artificial sunlight [125]. This was explained by the formation of silver oxalate, which absorbed from the visible region and was subsequently degraded.

Not all doping in NTO will exhibit positive effects, as reported in the cases of rhodium, carbon, and platinum doping. Rhodium doping afforded the highest activity for microcystin-LR degradation under visible light, followed by the carbon-doped catalyst [50]. In contrast, the platinum-doped NTO catalyst did not exhibit efficient visible light degradation because of the interference from chloride radicals generated by the homolytic cleavage of the platinum-chlorine bond in the platinum precursor. The synthetic route for the doped NTO catalyst also influences its activity. For example, hydrothermally derived vanadium-doped $\mathrm{TiO}_{2}$ showed higher activity than its sol-gel-derived counterpart in the degradation of an aqueous solution of isobutanol [122]. The addition of ammonium fluoride during hydrothermal treatment caused further enhancement in the activity of doped catalyst. The higher crystallinity resulting from the hydrothermal treatment and the hydrophobic surface formation by ammonium fluoride were responsible for these observations [122]. Heat treatment has a great influence in the characteristics and activity of doped NTO catalysts, especially in the case of nitrogen doping. Gohin et al. [128] observed a color change of anatase nanoparticles from slight yellow (at $500{ }^{\circ} \mathrm{C}$ ) to darkish green (above $650^{\circ} \mathrm{C}$ ) at different nitridation temperatures using urea as a nitrogen source. The yellow color at $500{ }^{\circ} \mathrm{C}$ resulted from the formation of localized $\mathrm{N} 2 \mathrm{p}$ states above the $\mathrm{VB}$ of $\mathrm{TiO}_{2}$. However, the darkish green color change, observed above $650{ }^{\circ} \mathrm{C}$, was due to the reduction of $\mathrm{Ti}^{4+}$ in anatase to $\mathrm{Ti}^{3+}$ by ammonia (from the decomposition of the urea precursor). These $\mathrm{Ti}^{3+}$ species were found to have detrimental effects on photocatalytic activity because they can act as recombination centers. The sample nitridated at $500{ }^{\circ} \mathrm{C}$ exhibited superior photocatalytic activity under visible light 
irradiation. However, whether $\mathrm{Ti}^{3+}$ in doped NTO can reduce [130] or increase $[98,128]$ the electron-hole pair recombination is still open to debate. The selection of pollutants is very important in visible light-induced photocatalytic degradation using doped NTO catalysts [125,129]. For example, when 4-methoxyresorcinol, quinoline, and 1-(p-anisyl)neopentanol were subjected to visible light photocatalytic degradation with sulfur-doped $\mathrm{TiO}_{2}$ (sol-gel method), only 4-methoxyresorcinol (at $\mathrm{pH}=8.5$ ) was destroyed [129]. The reason was the formation of a charge transfer complex (which absorbed the visible light) between 4-methoxyresorcinol and the catalyst, whereas quinoline and 1-( $p$-anisyl)neopentanol cannot form such charge transfer complexes. This limits the use of the abovementioned sulfur-doped $\mathrm{TiO}_{2}$ catalyst in the degradation of compounds that cannot form charge transfer complexes. Other factors that influence the activity of the doped NTO catalyst include dopant concentration [124,126], the crystal phase of the NTO [127], and the intensity of light irradiance [105]. Doped NTO photocatalysts have also been reported for their photocatalytic activity with UV light irradiation in pollutant degradation [131,132], nitrate reduction, and in bacterial disinfection [133,134].

Even though doped NTO catalysts can operate in the visible region, several issues must be considered before their wide use in photocatalytic water treatment. The visible light photocatalytic activity in most of the bulk modified NTO is far lower than the activity of unmodified catalyst under UV irradiation [50,122,129]. In addition, NTO catalysts modified by metal/non-metal doping sometimes have poor activity under UV irradiation [50,122,129]. Here, the doped species could act as recombination centers. Leaching of the doped species is another problem [129], which is a serious concern, especially when the dopants are toxic metals. Furthermore, doping is never a guarantee of high photoreactivity in the doped NTO catalyst, since reactivity is a complex function of dopant concentration, distribution, energy levels in the $\mathrm{TiO}_{2}$ lattice, d-electron configuration, and light intensity [135]. The choice of doped $\mathrm{TiO}_{2}$ as a photocatalyst versus un-doped $\mathrm{TiO}_{2}$ only depends on whether the requirement of low efficiency visible light activity outweighs the higher performance of photocatalysis under UV light [129]. Sometimes, even the smaller fraction of UV radiation in solar light can degrade selected pollutants effectively with unmodified NTO (Figure 5) [45].

\section{Coupling with Other Treatment Technologies}

Combining NTO photocatalysis with other oxidation techniques was found to be very effective in pollutant destruction. These technologies include electrocatalysis [35,136-138], sonocatalysis/Fenton process [139], biodegradation [140-144], and wetland technology [145]. The combination of NTO photocatalysis with any of these techniques can not only improve the total efficiency of the degradation but also has the advantage of treating large quantities of wastewater (in real systems), especially with electrocatalysis, biodegradation, and wetland technology. Electrocoagulation (using an iron cathode/anode $(12.50 \mathrm{~cm} \times 2.50 \mathrm{~cm} \times 0.10 \mathrm{~cm})$ at a current density of $763 \mathrm{Am}^{-2}$ for $\left.90 \mathrm{~min}\right)$ of an effluent from pharmaceutical and cosmetic companies removed the majority of the suspended particles, followed by further purification using NTO photocatalysis [35]. 
Table 3. Recent examples of metal- and non-metal-doped NTO photocatalysis.

\begin{tabular}{|c|c|c|c|}
\hline Doped catalyst & Synthesis route & Pollutant & Ref. \\
\hline Vanadium $/ \mathrm{TiO}_{2}(\lambda>430 \mathrm{~nm})$ & $\begin{array}{l}\text { sol-gel and } \\
\text { hydrothermal }\end{array}$ & isobutanol & [122] \\
\hline $\operatorname{Iron} / \mathrm{TiO}_{2}(\lambda>420 \mathrm{~nm})$ & $\begin{array}{l}\text { co-thermal } \\
\text { hydrolysis }\end{array}$ & methyl orange & [123] \\
\hline $\begin{array}{l}\text { Rhodium/TiO } \\
\text { Silver/P25 }\end{array}$ & impregnation & microcystin-LR & [50] \\
\hline artificial solar light & photoreduction & oxalic acid & [125] \\
\hline solar irradiation & electrospinning & E. coli & [92] \\
\hline Sulfur/ $\mathrm{TiO}_{2}$ (495 nm filter) & sol-gel & $\begin{array}{l}\text { 4-methoxyresorcinol, } \\
\text { quinoline \&1-(p anisyl) } \\
\text { neopentanol }\end{array}$ & [129] \\
\hline$(\lambda>420 \mathrm{~nm})$ & $\begin{array}{l}\text { sol-gel, self- } \\
\text { assembly }\end{array}$ & microcystin-LR & [98] \\
\hline Nitrogen/P25 $(\lambda>420 \mathrm{~nm})$ & milling & rhodamine B & [127] \\
\hline Nitrogen/TiO 2 & & & \\
\hline$(\lambda=390 \& 470 \mathrm{~nm})$ & sol-gel & rhodamine $6 \mathrm{G}$ & [128] \\
\hline Solar and visible light & sol-gel & microcystin-LR & [51] \\
\hline Carbon/ $/ \mathrm{TiO}_{2}$ (Artificial solar light) & $\begin{array}{l}\text { high pressure } \\
\text { heating }\end{array}$ & methylene blue & [126] \\
\hline $\begin{array}{l}\text { Iodine } / \mathrm{TiO}_{2} \text { (spectrum close to } \\
\text { sunlight) }\end{array}$ & hydrothermal & phenol & [130] \\
\hline $\begin{array}{l}\text { Nitrogen-Palladium co-doped } \mathrm{TiO}_{2} \\
\text { (visible light) }\end{array}$ & sol-gel & eosin yellow & [124] \\
\hline $\begin{array}{l}\text { Carbon-nitrogen co-doped } \mathrm{TiO}_{2}(\lambda= \\
465,523 \& 589 \mathrm{~nm})\end{array}$ & solvothermal & bisphenol A & [105] \\
\hline $\begin{array}{l}\text { Fluorine-nitrogen co-doped } \mathrm{TiO}_{2} \\
(\lambda>420 \mathrm{~nm})\end{array}$ & sol-gel & microcystin-LR & [96] \\
\hline
\end{tabular}

The effluent had an initial chemical oxygen demand (COD) value of $1753 \mathrm{mg} \mathrm{L}^{-1}$, which was reduced to $160 \mathrm{mg} \mathrm{L}^{-1}$ and $50 \mathrm{mg} \mathrm{L}^{-1}$ after electrocoagulation and electrocoagulation/photocatalysis, respectively. Here, the electrocoagulation pre-treatment removed the suspended particles, and thus, the turbidity in the effluent. Thereby, the working load of the $\mathrm{TiO}_{2}$ catalyst was reduced and the transparency of the medium was increased, such that UV radiation could pass through easily. In an another study, the synergic effect of $\mathrm{TiO}_{2}$ photocatalysis and boron-doped diamond (BDD) anodic oxidation improved the total organic carbon (TOC) reduction in the degradation of $\mathrm{X}-3 \mathrm{~B}$ dye in an experimental set up, as shown in Figure 6a [136]. Figure 6b represents the efficiency (as a function of time) of different reaction systems employed in the decolorization of X-3B dye, in which the systems using $\mathrm{TiO}_{2}$ photocatalysis and BDD anodic oxidation showed the highest activities. The removal of bromate by reduction to bromide [137] and the degradation of chlortetracycline [138] in high efficiencies were also achieved by photoelectrocatalysis using $\mathrm{Ti} / \mathrm{TiO}_{2}$ as the photocathode and photoanode, respectively. Another example for the synergic effect of different AOPs is the combined ultrasound-, Fenton-, and $\mathrm{TiO}_{2}$-photoassisted mineralization of bisphenol A [139]. By this combined 
approach, 93\% dissolved organic carbon (DOC) removal was achieved, whereas DOC removals by the individual processes were 5,6 , and $22 \%$ for $\mathrm{TiO}_{2}$ photocatalysis, ultrasound, and photo-Fenton, respectively [139]. Here, ultrasound eliminated the initial substrate and provided $\mathrm{H}_{2} \mathrm{O}_{2}$ for the photocatalytic reactions. $\mathrm{TiO}_{2}$ photocatalysis and photo- Fenton treatments were mainly responsible for the total mineralization of the intermediates generated by the ultrasound technique.

Figure 5. Photocatalytic degradation of microcystin-LR under (a) solar light irradiation and (b) visible light (440-460 nm), in the presence of commercial (P25 and Kronos), reference $\left(\right.$ Ref- $\left.-\mathrm{TiO}_{2}\right)$, and nitrogen-doped $\left(\mathrm{N}-\mathrm{TiO}_{2}\right) \mathrm{TiO}_{2}$ materials. (Reprinted from [51]. Copyright (2012), with permission from Elsevier).

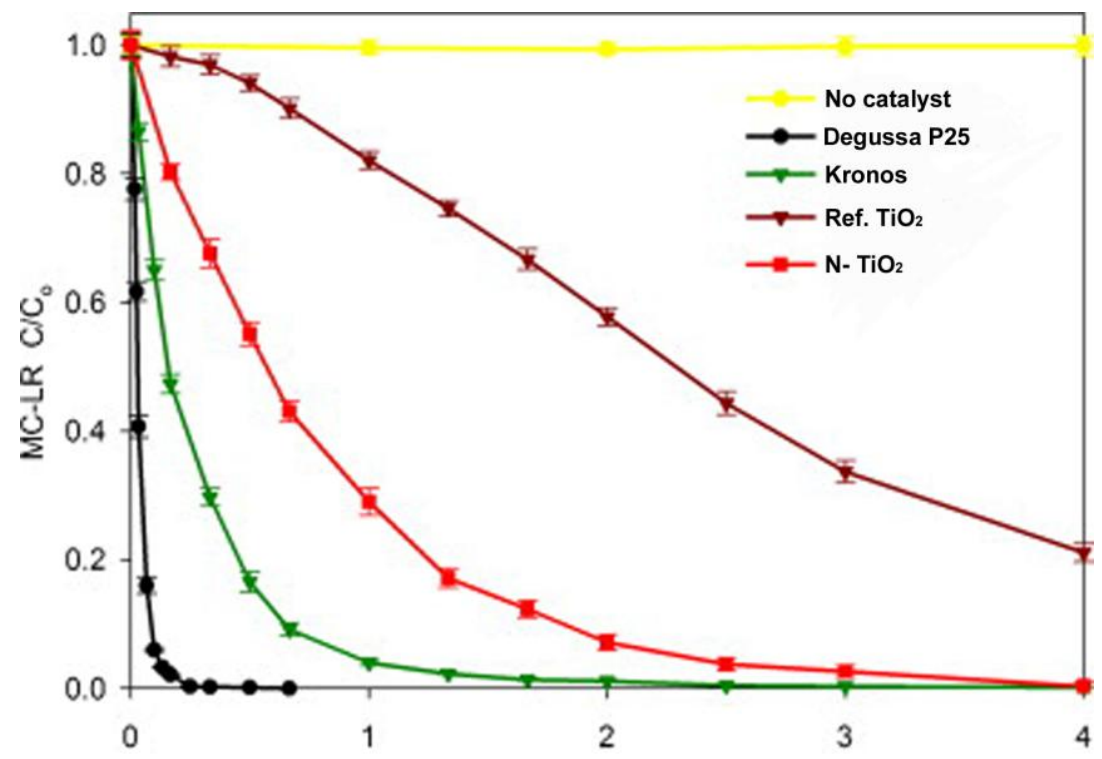

(a)

Photolysis time (h)

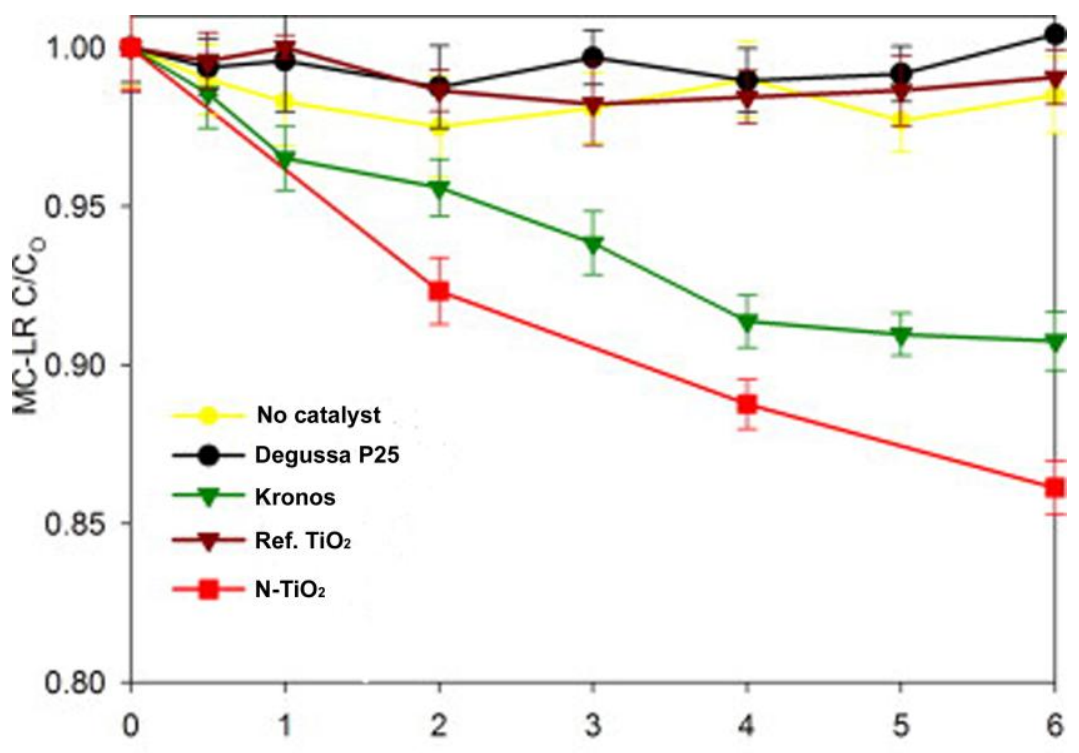

(b)

Photolysis time (h)

Biological oxidation is one of the oldest techniques for water treatment. The combination of biological oxidation followed by NTO photocatalysis was employed (Figure 7a) for the mineralization 
of a mixture containing 2-chlorophenol, 2,4-dichlorophenol, 2,4,5-trichlorophenol, and pentachlorophenol in tap water (total concentration was $100 \mathrm{mg} \mathrm{L}^{-1}$, each component was $25 \mathrm{mg} \mathrm{L}^{-1}$ ) [140]. The order of the treatments was very important, as the combined biological-photocatalytic treatment removed chlorophenols at a rate of $25.8 \mathrm{mg} \mathrm{h}^{-1}$, whereas, for the combined photocatalytic-biological treatment, the removal rate was only $10.5 \mathrm{mg} \mathrm{h}^{-1}$. Similar observations were reported for the degradation of dyes [141], cyproconazole [142], and a tetracycline/tylosin mixture [143], in which the $\mathrm{TiO}_{2}$ photocatalytic pre-treatment eradicated the activity of biological oxidation. In this case, some of the intermediates generated during photocatalysis were not biodegradable. In contrast to the above observations, Chen et al. reported the feasibility of using NTO photocatalysis as a pre-treatment followed by the use of a constructed wetland [145]. In their experiment (Figure 7b), they initially treated domestic and agricultural wastewaters (COD was $36.2 \pm 7.4$ ) by $\mathrm{TiO}_{2}$ (coated on $\alpha$-alumina) photocatalysis before transfer to a bench-scale wetland system. With a hydraulic retention time of 2 days, they reduced the levels of halomethanes and haloacetic acids below the maximum allowed contamination thresholds for drinking water. The intermediates generated by the photocatalytic treatment were biodegradable, which made the wetland treatment fruitful. However, they did not attempt the wetland pre-treatment followed by NTO photocatalysis. From these contrasting observations, we think that the order of treatment is crucial, and varies according to the nature of the contaminants.

Figure 6. (a) Schematic of the anodic oxidation- and photocatalysis-coupled reactor and (b) comparison of degradation performance in different experimental systems [136].

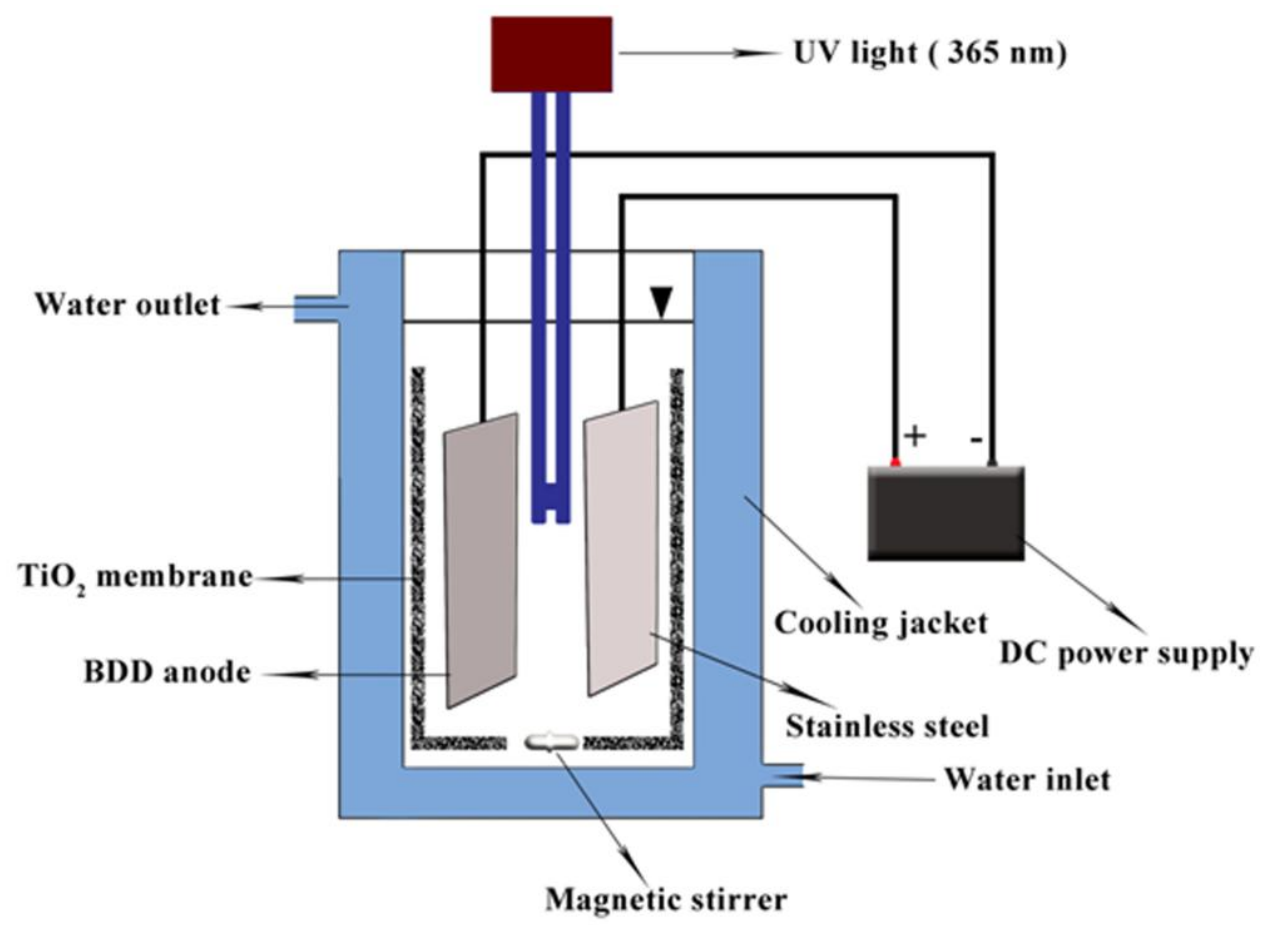

(a) 
Figure 6. Cont.

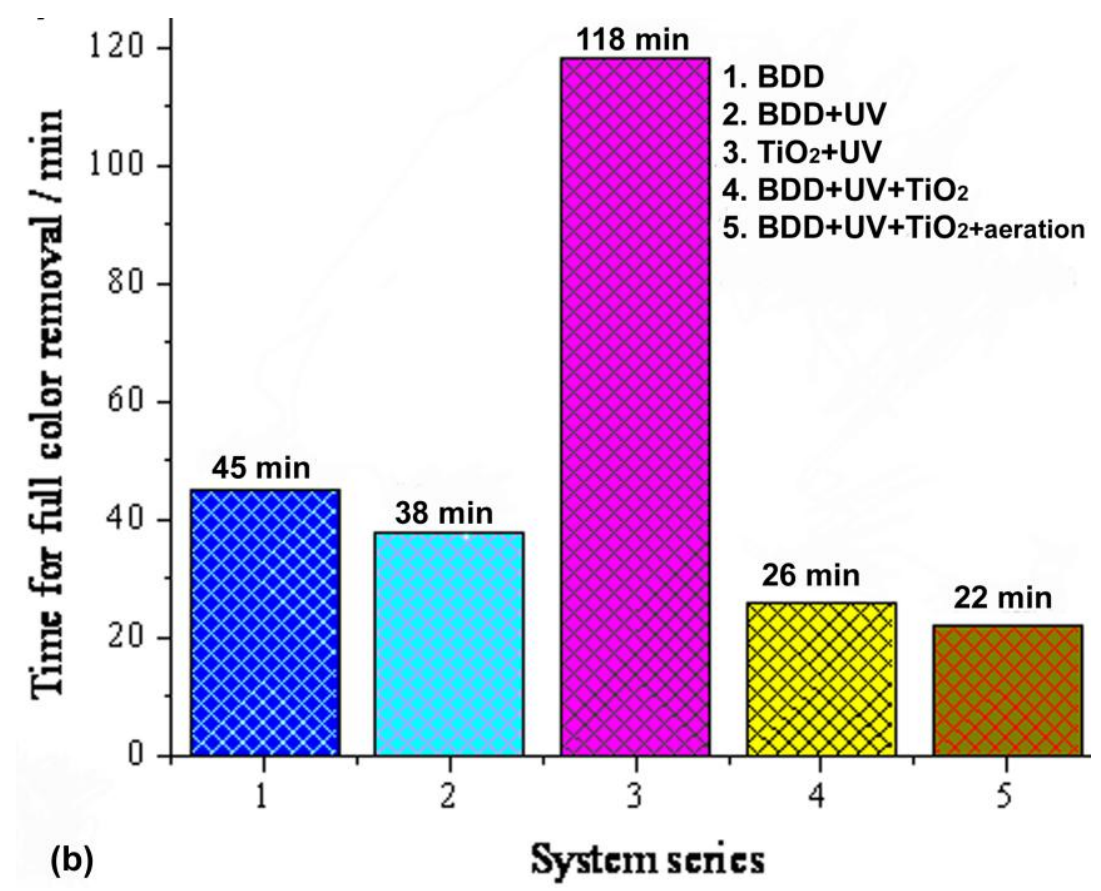

Figure 7. Schematic of the coupling of (a) biological [140] and (b) wetland treatment technologies [145] with photocatalysis.

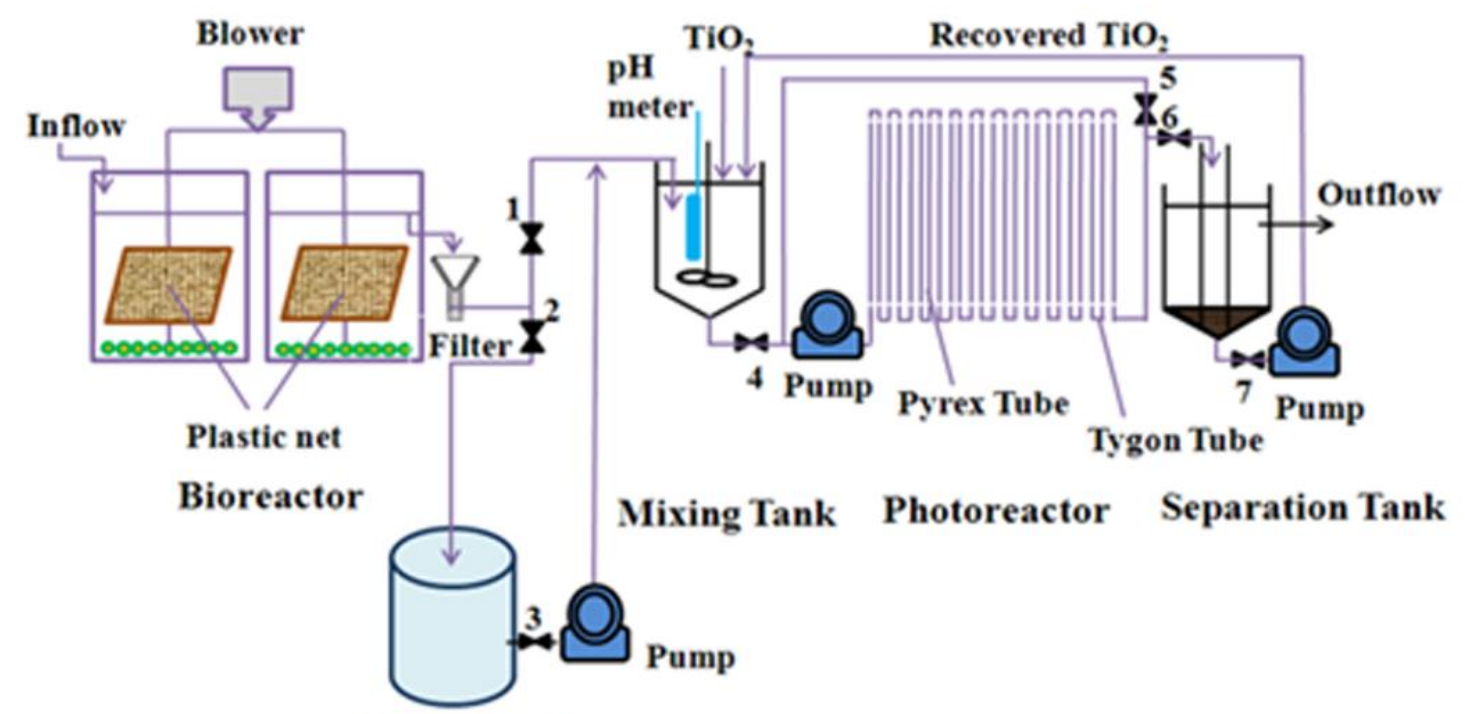

Reservoir Tank

(a) 
Figure 7. Cont.

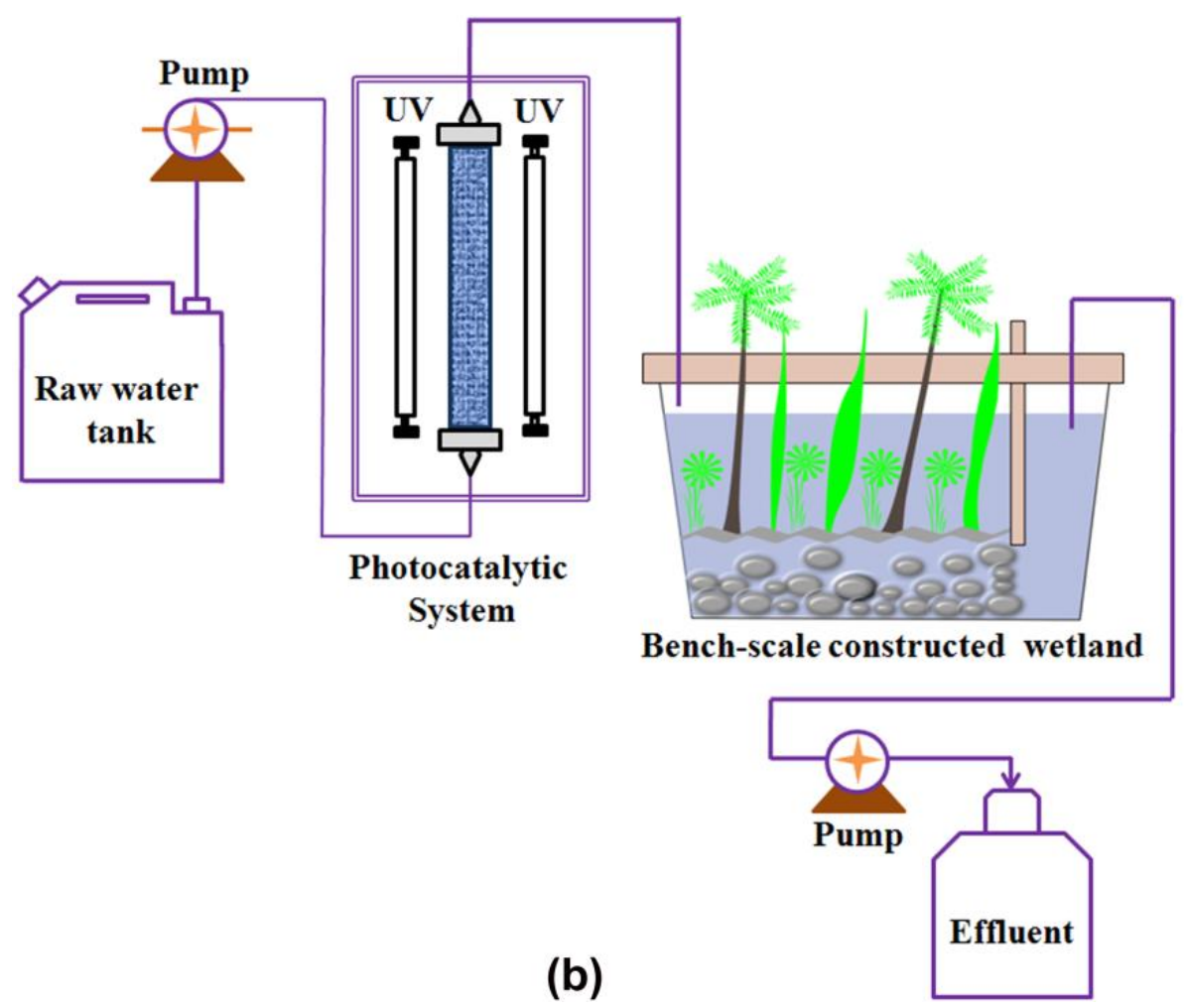

\section{Conclusions and Future Prospects}

Photocatalytic water treatment by NTO is a hot topic of environmental research and a versatile technique for pollutant degradation. Having a long history of active investigation since the 1970s, photocatalytic water treatment by NTO still retains its importance in contemporary research. This is because of the unique properties of $\mathrm{TiO}_{2}$, its ability to completely mineralize a wide spectrum of pollutants, its cheap operating costs, and simple experimental design. By reviewing recent developments in this area, the authors have arrived at the following conclusions.

- A large number of individual compounds have been successfully tested for photocatalytic degradation by NTO, and researchers are now more focused on real systems, which is promising for the commercialization of the technology. Selective photocatalysis by NTO is a potential research area where researchers can find several opportunities.

- $\quad$ Photocatalytic degradation of pollutants by NTO is mainly triggered by $\cdot \mathrm{OH}$ radicals, along with the direct oxidation of adsorbed pollutants by surface-generated holes; however, the latter is a minor secondary degradation pathway. The kinetics of photocatalytic degradation by NTO was found to depend on catalyst loading, the extent of adsorption, and light intensity. However, several reports claim that it follows L-H reaction kinetics, especially below catalyst saturation. This is an area where more studies must be conducted in order to clarify the ambiguities in photocatalytic degradation kinetics.

- Different NTO morphologies have been synthesized and found to be effective for the photocatalytic degradation of various compounds. Surface treatment of NTO is another option for increasing catalytic activity. 
- $\quad$ The design of photocatalytic reactors is a key area where intense research is in progress. An ideal photocatalytic reactor should be simple, energy efficient, less expensive to build and operate, and able to handle high wastewater volumes. Reactors operating with solar radiation or LEDs and reactor designs that do not require post separation of the catalyst hold great promise.

- Doping NTO with metals and non-metals was investigated to achieve absorption from the visible region by reducing the band gap of the doped catalyst. However, the practicability of applying doped NTO catalysts in photocatalytic water treatment needs reconsideration because of the low catalytic activity of the doped NTO catalysts under visible light and because of the possibility of dopant leaching.

- $\quad$ NTO photocatalysis in conjunction with other treatment technologies was explored by several groups. Coupling NTO photocatalysis with other technologies has great potential in large-scale water treatment, and further research is necessary.

\section{Acknowledgments}

This work was financially supported by Monash Research Graduate School (MRGS) and the Gippsland Campus, Monash. Manoj A. Lazar is grateful to Lane McDonald for the proof reading of the revisions.

\section{References}

1. Verhoeven, J.W. Glossary of terms used in photochemistry. Pure Appl. Chem. 1996, 68, 2223-2286.

2. Pelaez, M.; Nolan, N.T.; Pillai, S.C.; Seery, M.K.; Falaras, P.; Kontos, A.G.; Dunlop, P.S.M.; Hamilton, J.W.J.; Byrne, J.A.; O'Shea, K.; et al. A review on the visible light active titanium dioxide photocatalysts for environmental applications. Appl. Catal. B 2012, 125, 331-349.

3. Khin, M.M.; Nair, A.S.; Babu, V.J.; Murugan, R.; Ramakrishna, S. A review on nanomaterials for environmental remediation. Energy Environ. Sci. 2012, 5, 8075-8109.

4. Malato, S.; Fernandez-Ibanez, P.; Maldonado, M.I.; Blanco, J.; Gernjak, W. Decontamination and disinfection of water by solar photocatalysis: Recent overview and trends. Catal. Today 2009, 147, 1-59.

5. Chong, M.N.; Jin, B.; Chow, C.W.K.; Saint, C. Recent developments in photocatalytic water treatment technology: A review. Water Res. 2010, 44, 2997-3027.

6. Mills, A.; LeHunte, S. An overview of semiconductor photocatalysis. J. Photochem. Photobiol. A 1997, 108, 1-35.

7. Lofrano, G.; Rizzo, L.; Grassi, M.; Belgiorno, V. Advanced oxidation of catechol: A comparison among photocatalysis, fenton and photo-fenton processes. Desalination 2009, 249, 878-883.

8. Vilar, V.J.P.; Pinho, L.X.; Pintor, A.M.A.; Boaventura, R.A.R. Treatment of textile wastewaters by solar-driven advanced oxidation processes. Sol. Energy 2011, 85, 1927-1934.

9. Rizzo, L.; Meric, S.; Guida, M.; Kassinos, D.; Belgiorno, V. Heterogenous photocatalytic degradation kinetics and detoxification of an urban wastewater treatment plant effluent contaminated with pharmaceuticals. Water Res. 2009, 43, 4070-4078. 
10. Radjenovic, J.; Sirtori, C.; Petrovic, M.; Barcelo, D.; Malato, S. Solar photocatalytic degradation of persistent pharmaceuticals at pilot-scale: Kinetics and characterization of major intermediate products. Appl. Catal. B 2009, 89, 255-264.

11. Ghaly, M.Y.; Jamil, T.S.; El-Seesy, I.E.; Souaya, E.R.; Nasr, R.A. Treatment of highly polluted paper mill wastewater by solar photocatalytic oxidation with synthesized nano $\mathrm{TiO}_{2}$. Chem. Eng. J. 2011, 168, 446-454.

12. Sanchez, M.; Rivero, M.J.; Ortiz, I. Photocatalytic oxidation of grey water over titanium dioxide suspensions. Desalination 2010, 262, 141-146.

13. Miranda-Garcia, N.; Suarez, S.; Sanchez, B.; Coronado, J.M.; Malato, S.; Maldonado, M.I. Photocatalytic degradation of emerging contaminants in municipal wastewater treatment plant effluents using immobilized $\mathrm{TiO}_{2}$ in a solar pilot plant. Appl. Catal. B 2011, 103, 294-301.

14. Saravanan, P.; Pakshirajan, K.; Saha, P. Degradation of phenol by $\mathrm{TiO}_{2}$-based heterogeneous photocatalysts in presence of sunlight. J. Hydro-Environ. Res. 2009, 3, 45-50.

15. Poblete, R.; Otal, E.; Vilches, L.F.; Vale, J.; Fernandez-Pereira, C. Photocatalytic degradation of humic acids and landfill leachate using a solid industrial by-product containing $\mathrm{TiO}_{2}$ and $\mathrm{Fe}$. Appl. Catal. B 2011, 102, 172-179.

16. Kim, J.; Choi, W. Hydrogen producing water treatment through solar photocatalysis. Energy Environ. Sci. 2010, 3, 1042-1045.

17. Sharabi, D.; Paz, Y. Preferential photodegradation of contaminants by molecular imprinting on titanium dioxide. Appl. Catal. B 2010, 95, 169-178.

18. Zhang, G.; Choi, W.; Kim, S.H.; Hong, S.B. Selective photocatalytic degradation of aquatic pollutants by titania encapsulated into FAU-type zeolites. J. Hazard. Mater. 2011, 188, 198-205.

19. Lazar, M.A.; Daoud, W.A. Selective adsorption and photocatalysis of low-temperature base-modified anatase nanocrystals. RSC Adv. 2012, 2, 447-452.

20. Medana, C.; Calza, P.; Dal Bello, F.; Raso, E.; Minero, C.; Baiocchi, C. Multiple unknown degradants generated from the insect repellent deet by photoinduced processes on $\mathrm{TiO}_{2}$. J. Mass Spectrom. 2011, 46, 24-40.

21. Sirtori, C.; Zapata, A.; Malato, S.; Gernjak, W.; Fernandez-Alba, A.R.; Aguera, A. Solar photocatalytic treatment of quinolones: Intermediates and toxicity evaluation. Photochem. Photobiol. Sci. 2009, 8, 644-651.

22. Lopez-Alvarez, B.; Torres-Palma, R.A.; Penuela, G. Solar photocatalitycal treatment of carbofuran at lab and pilot scale: Effect of classical parameters, evaluation of the toxicity and analysis of organic by-products. J. Hazard. Mater. 2011, 191, 196-203.

23. Lu, C.-S.; Chen, C.-C.; Mai, F.-D.; Li, H.-K. Identification of the degradation pathways of alkanolamines with $\mathrm{TiO}_{2}$ photocatalysis. J. Hazard. Mater. 2009, 165, 306-316.

24. Stapleton, D.R.; Konstantinou, I.K.; Mantzavinos, D.; Hela, D.; Papadaki, M. On the kinetics and mechanisms of photolytic/ $/ \mathrm{TiO}_{2}$-photocatalytic degradation of substituted pyridines in aqueous solutions. Appl. Catal. B 2010, 95, 100-109.

25. An, T.C.; An, J.B.; Yang, H.; Li, G.Y.; Feng, H.X.; Nie, X.P. Photocatalytic degradation kinetics and mechanism of antivirus drug-lamivudine in $\mathrm{TiO}_{2}$ dispersion. J. Hazard. Mater. 2011, 197, 229-236. 
26. Lin, Y.; Ferronato, C.; Deng, N.; Wu, F.; Chovelon, J.-M. Photocatalytic degradation of methylparaben by $\mathrm{TiO}_{2}$ : Multivariable experimental design and mechanism. Appl. Catal. B 2009, $88,32-41$.

27. Chung, Y.-C.; Chen, C.-Y. Degradation of azo dye reactive violet 5 by $\mathrm{TiO}_{2}$ photocatalysis. Environ. Chem. Lett. 2009, 7, 347-352.

28. Dias, M.G.; Azevedo, E.B. Photocatalytic decolorization of commercial acid dyes using solar irradiation. Water Air Soil Pollut. 2009, 204, 79-87.

29. Lopez, L.; Daoud, W.A.; Dutta, D. Preparation of large scale photocatalytic $\mathrm{TiO}_{2}$ films by the sol-gel process. Surf. Coat. Technol. 2010, 205, 251-257.

30. Esparza, P.; Borges, M.E.; Diaz, L.; Alvarez-Galvan, M.C.; Fierro, J.L.G. Photodegradation of dye pollutants using new nanostructured titania supported on volcanic ashes. Appl. Catal. A 2010, 388, 7-14.

31. Zhuang, J.D.; Dai, W.X.; Tian, Q.F.; Li, Z.H.; Xie, L.Y.; Wang, J.X.; Liu, P.; Shi, X.C.; Wang, D.H. Photocatalytic degradation of rhb over $\mathrm{TiO}_{2}$ bilayer films: Effect of defects and their location. Langmuir 2010, 26, 9686-9694.

32. Echavia, G.R.M.; Matzusawa, F.; Negishi, N. Photocatalytic degradation of organophosphate and phosphonoglycine pesticides using $\mathrm{TiO}_{2}$ immobilized on silica gel. Chemosphere 2009, 76, 595-600.

33. Pelentridou, K.; Stathatos, E.; Karasali, H.; Lianos, P. Photodegradation of the herbicide azimsulfuron using nanocrystalline titania films as photocatalyst and low intensity black light radiation or simulated solar radiation as excitation source. J. Hazard. Mater. 2009, 163, 756-760.

34. Fabbri, D.; Crime, A.; Davezza, M.; Medana, C.; Baiocchi, C.; Prevot, A.B.; Pramauro, E. Surfactant-assisted removal of swep residues from soil and photocatalytic treatment of the washing wastes. Appl. Catal. B 2009, 92, 318-325.

35. Boroski, M.; Rodrigues, A.C.; Garcia, J.C.; Sampaio, L.C.; Nozaki, J.; Hioka, N. Combined electrocoagulation and $\mathrm{TiO}_{2}$ photoassisted treatment applied to wastewater effluents from pharmaceutical and cosmetic industries. J. Hazard. Mater. 2009, 162, 448-454.

36. Choina, J.; Duwensee, H.; Flechsig, G.U.; Kosslick, H.; Morawski, A.W.; Tuan, V.A.; Schulz, A. Removal of hazardous pharmaceutical from water by photocatalytic treatment. Cent. Eur. J. Chem. 2010, 8, 1288-1297.

37. Alvarez, P.M.; Jaramillo, J.; Lopez-Pinero, F.; Plucinski, P.K. Preparation and characterization of magnetic $\mathrm{TiO}_{2}$ nanoparticles and their utilization for the degradation of emerging pollutants in water. Appl. Catal. B 2010, 100, 338-345.

38. Lin, Y.X.; Ferronato, C.; Deng, N.S.; Chovelon, J.M. Study of benzylparaben photocatalytic degradation by $\mathrm{TiO}_{2}$. Appl. Catal. B 2011, 104, 353-360.

39. Giraldo, A.L.; Penuela, G.A.; Torres-Palma, R.A.; Pino, N.J.; Palominos, R.A.; Mansilla, H.D. Degradation of the antibiotic oxolinic acid by photocatalysis with $\mathrm{TiO}_{2}$ in suspension. Water Res. 2010, 44, 5158-5167.

40. Hapeshi, E.; Achilleos, A.; Vasquez, M.I.; Michael, C.; Xekoukoulotakis, N.P.; Mantzavinos, D.; Kassinos, D. Drugs degrading photocatalytically: Kinetics and mechanisms of ofloxacin and atenolol removal on titania suspensions. Water Res. 2010, 44, 1737-1746. 
41. Ioannou, L.A.; Hapeshi, E.; Vasquez, M.I.; Mantzavinos, D.; Fatta-Kassinos, D. Solar/TiO 2 photocatalytic decomposition of beta-blockers atenolol and propranolol in water and wastewater. Sol. Energy 2011, 85, 1915-1926.

42. An, T.C.; Yang, H.; Li, G.Y.; Song, W.H.; Cooper, W.J.; Nie, X.P. Kinetics and mechanism of advanced oxidation processes (AOPs) in degradation of ciprofloxacin in water. Appl. Catal. B 2010, 94, 288-294.

43. Li, W.; Guo, C.; Su, B.; Xu, J. Photodegradation of four fluoroquinolone compounds by titanium dioxide under simulated solar light irradiation. J. Chem. Technol. Biotechnol. 2012, 87, 643-650.

44. Pereira, J.; Vilar, V.J.P.; Borges, M.T.; Gonzalez, O.; Esplugas, S.; Boaventura, R.A.R. Photocatalytic degradation of oxytetracycline using $\mathrm{TiO}_{2}$ under natural and simulated solar radiation. Sol. Energy 2011, 85, 2732-2740.

45. Adams, W.A.; Impellitteri, C.A. The photocatalysis of n,n-diethyl-m-toluamide (DEET) using dispersions of degussa p-25 $\mathrm{TiO}_{2}$ particles. J. Photochem. Photobiol. A 2009, 202, 28-32.

46. Qourzal, S.; Barka, N.; Tamimi, M.; Assabbane, A.; Nounah, A.; Ihlal, A.; Ait-Ichou, Y. Sol-gel synthesis of $\mathrm{TiO}_{2}-\mathrm{SiO}_{2}$ photocatalyst for beta-naphthol photodegradation. Mater. Sci. Eng. C 2009, 29, 1616-1620.

47. Miranda-Garcia, N.; Maldonado, M.I.; Coronado, J.M.; Malato, S. Degradation study of 15 emerging contaminants at low concentration by immobilized $\mathrm{TiO}_{2}$ in a pilot plant. Catal. Today 2010, 151, 107-113.

48. Antoniou, M.G.; Shoemaker, J.A.; de la Cruz, A.A.; Dionysiou, D.D. LC/MS/MS structure elucidation of reaction intermediates formed during the $\mathrm{TiO}_{2}$ photocatalysis of microcystin-LR. Toxicon 2008, 51, 1103-1118.

49. Sharma, V.K.; Triantis, T.M.; Antoniou, M.G.; He, X.X.; Pelaez, M.; Han, C.S.; Song, W.H.; O'Shea, K.E.; de la Cruz, A.A.; Kaloudis, T.; et al. Destruction of microcystins by conventional and advanced oxidation processes: A review. Sep. Purif. Technol. 2012, 91, 3-17.

50. Graham, D.; Kisch, H.; Lawton, L.A.; Robertson, P.K.J. The degradation of microcystin-LR using doped visible light absorbing photocatalysts. Chemosphere 2010, 78, 1182-1185.

51. Triantis, T.M.; Fotiou, T.; Kaloudis, T.; Kontos, A.G.; Falaras, P.; Dionysiou, D.D.; Pelaez, M.; Hiskia, A. Photocatalytic degradation and mineralization of microcystin-LR under UV-A, solar and visible light using nanostructured nitrogen doped $\mathrm{TiO}_{2}$. J. Hazard. Mater. 2012, 211, 196-202.

52. Dalrymple, O.K.; Isaacs, W.; Stefanakos, E.; Trotz, M.A.; Goswami, D.Y. Lipid vesicles as model membranes in photocatalytic disinfection studies. J. Photochem. Photobiol. A 2011, 221, 64-70.

53. Amarjargal, A.; Tijing, L.D.; Yu, M.-H.; Kim, C.-H.; Park, C.-H.; Kim, D.-W.; Kim, C.-S. Characterization and photocatalytic efficiency of $\mathrm{TiO}_{2} / \mathrm{Ti}$ beads fabricated by simple heat-treatment. J. Mater. Sci. Technol. 2012, 28, 184-192.

54. Li, G.Z.; Park, S.; Kang, D.W.; Krajmalnik-Brown, R.; Rittmann, B.E. 2,4,5-trichlorophenol degradation using a novel $\mathrm{TiO}_{2}$-coated biofilm carrier: Roles of adsorption, photocatalysis, and biodegradation. Environ. Sci. Technol. 2011, 45, 8359-8367.

55. Zhang, W.; Li, Y.; Su, Y.; Mao, K.; Wang, Q. Effect of water composition on $\mathrm{TiO}_{2}$ photocatalytic removal of endocrine disrupting compounds (EDCs) and estrogenic activity from secondary effluent. J. Hazard. Mater. 2012, 215, 252-258. 
56. Wang, T.C.; Lu, N.; Li, J.; Wu, Y. Plasma-TiO 2 catalytic method for high-efficiency remediation of p-nitrophenol contaminated soil in pulsed discharge. Environ. Sci. Technol. 2011, 45, 9301-9307.

57. Wang, C.; Zhang, X.; Liu, H.; Li, X.; Li, W.; Xu, H. Reaction kinetics of photocatalytic degradation of sulfosalicylic acid using $\mathrm{TiO}_{2}$ microspheres. J. Hazard. Mater. 2009, 163, 1101-1106.

58. Montoya, J.F.; Velasquez, J.A.; Salvador, P. The direct-indirect kinetic model in photocatalysis: A reanalysis of phenol and formic acid degradation rate dependence on photon flow and concentration in $\mathrm{TiO}_{2}$ aqueous dispersions. Appl. Catal. B 2009, 88, 50-58.

59. Tasseroul, L.; Pirard, S.L.; Lambert, S.D.; Paez, C.A.; Poelman, D.; Pirard, J.-P.; Heinrichs, B. Kinetic study of p-nitrophenol photodegradation with modified $\mathrm{TiO}_{2}$ xerogels. Chem. Eng. J. 2012, 191, 441-450.

60. Emeline, A.V.; Ryabchuk, V.K.; Serpone, N. Dogmas and misconceptions in heterogeneous photocatalysis. Some enlightened reflections. J. Phys. Chem. B 2005, 109, 18515-18521.

61. Pelaez, M.; de la Cruz, A.A.; O’Shea, K.; Falaras, P.; Dionysiou, D.D. Effects of water parameters on the degradation of microcystin-LR under visible light-activated $\mathrm{TiO}_{2}$ photocatalyst. Water Res. 2011, 45, 3787-3796.

62. Wang, W.; Lu, C.; Ni, Y.; Peng, F.; Xu, Z. Enhanced performance of $\{001\}$ facets dominated mesoporous $\mathrm{TiO}_{2}$ photocatalyst composed of high-reactive nanocrystals and mesoporous spheres. Appl. Surf. Sci. doi:10.1016/j.apsusc.2012.11.025.

63. Zhao, Z.; Sun, Z.C.; Zhao, H.F.; Zheng, M.; Du, P.; Zhao, J.L.; Fan, H.Y. Phase control of hierarchically structured mesoporous anatase $\mathrm{TiO}_{2}$ microspheres covered with $\{001\}$ facets. $J$. Mater. Chem. 2012, 22, 21965-21971.

64. Ismail, A.A.; Bahnemann, D.W.; Robben, L.; Yarovyi, V.; Wark, M. Palladium doped porous titania photocatalysts: Impact of mesoporous order and crystallinity. Chem. Mat. 2010, 22, 108-116.

65. Liu, J.N.; Zhang, G.W.; Ao, W.; Yang, K.; Peng, S.X.; Muller-Goymann, C. Hollow mesoporous titania microsphere with low shell thickness/diameter ratio and high photocatalysis. Appl. Surf. Sci. 2012, 258, 8083-8089.

66. Joo, J.B.; Zhang, Q.; Dahl, M.; Lee, I.; Goebl, J.; Zaera, F.; Yin, Y.D. Control of the nanoscale crystallinity in mesoporous $\mathrm{TiO}_{2}$ shells for enhanced photocatalytic activity. Energy. Environ. Sci. 2012, 5, 6321-6327.

67. Ismail, A.A.; Bahnemann, D.W. Mesoporous titania photocatalysts: Preparation, characterization and reaction mechanisms. J. Mater. Chem. 2011, 21, 11686-11707.

68. Nakata, K.; Fujishima, A. $\mathrm{TiO}_{2}$ photocatalysis: Design and applications. J. Photochem. Photobiol. C 2012, 13, 169-189.

69. Pan, J.H.; Dou, H.Q.; Xiong, Z.G.; Xu, C.; Ma, J.Z.; Zhao, X.S. Porous photocatalysts for advanced water purifications. J. Mater. Chem. 2010, 20, 4512-4528.

70. Robben, L.; Ismail, A.A.; Lohmeier, S.J.; Feldhoff, A.; Bahnemann, D.W.; Buhl, J.C. Facile synthesis of highly ordered mesoporous and well crystalline $\mathrm{TiO}_{2}$ : Impact of different gas atmosphere and calcination temperatures on structural properties. Chem. Mat. 2012, 24, 1268-1275.

71. Han, C.; Luque, R.; Dionysiou, D.D. Facile preparation of controllable size monodisperse anatase titania nanoparticles. Chem. Commun. 2012, 48, 1860-1862.

72. Chen, D.H.; Huang, F.Z.; Cao, L.; Cheng, Y.B.; Caruso, R.A. Spiky mesoporous anatase titania beads: A metastable ammonium titanate-mediated synthesis. Chem. Eur. J. 2012, 18, 13762-13769. 
73. Zhang, X.; Pan, J.H.; Du, A.J.; Fu, W.; Sun, D.D.; Leckie, J.O. Combination of one-dimensional $\mathrm{TiO}_{2}$ nanowire photocatalytic oxidation with microfiltration for water treatment. Water Res. 2009, 43, 1179-1186.

74. Zhang, A.Y.; Zhou, M.H.; Han, L.; Zhou, Q.X. The combination of rotating disk photocatalytic reactor and $\mathrm{TiO}_{2}$ nanotube arrays for environmental pollutants removal. J. Hazard. Mater. 2011, 186, 1374-1383.

75. Sun, X.; Zhang, J.; Zhang, G.; Pan, X.; Huang, T. Preparation and characteristics of $\mathrm{TiO}_{2}$ nanotube catalysts used in hybrid photocatalysis/membrane process. Catal. Commun. 2012, 18, 76-80.

76. Zhang, X.; Pan, J.H.; Du, A.J.; Xu, S.; Sun, D.D. Room-temperature fabrication of anatase $\mathrm{TiO}_{2}$ submicrospheres with nanothornlike shell for photocatalytic degradation of methylene blue. $J$. Photochem. Photobiol. A 2009, 204, 154-160.

77. Farbod, M.; Khademalrasool, M. Synthesis of $\mathrm{TiO}_{2}$ nanoparticles by a combined sol-gel ball milling method and investigation of nanoparticle size effect on their photocatalytic activities. Powder Technol. 2011, 214, 344-348.

78. Li, G.; Lv, L.; Fan, H.T.; Ma, J.Y.; Li, Y.Q.; Wan, Y.; Zhao, X.S. Effect of the agglomeration of $\mathrm{TiO}_{2}$ nanoparticles on their photocatalytic performance in the aqueous phase. J. Colloid Interface Sci. 2010, 348, 342-347.

79. Mogyorosi, K.; Balazs, N.; Sranko, D.F.; Tombacz, E.; Dekany, I.; Oszko, A.; Sipos, P.; Dombi, A. The effect of particle shape on the activity of nanocrystalline $\mathrm{TiO}_{2}$ photocatalysts in phenol decomposition. Part 3: The importance of surface quality. Appl. Catal. B 2010, 96, 577-585.

80. Bizarro, M.; Tapia-Rodriguez, M.A.; Ojeda, M.L.; Alonso, J.C.; Ortiz, A. Photocatalytic activity enhancement of $\mathrm{TiO}_{2}$ films by micro and nano-structured surface modification. Appl. Surf. Sci. 2009, 255, 6274-6278.

81. Monllor-Satoca, D.; Lana-Villarreal, T.; Gomez, R. Effect of surface fluorination on the electrochemical and photoelectrocatalytic properties of nanoporous titanium dioxide electrodes. Langmuir 2011, 27, 15312-15321.

82. Kim, M.J.; Kim, K.D.; Tai, W.S.; Seo, H.O.; Luo, Y.; Kim, Y.D.; Lee, B.C.; Park, O.K. Enhancement of photocatalytic activity of $\mathrm{TiO}_{2}$ by high-energy electron-beam treatment under atmospheric pressure. Catal. Lett. 2010, 135, 57-61.

83. Zou, W.W.; Zhang, J.L.; Chen, F. Preparation, characterization and application of $\mathrm{TiO}_{2}$ nanoparticles surface-modified by DDAT. Mater. Lett. 2010, 64, 1710-1712.

84. Shan, A.Y.; Ghazi, T.I.M.; Rashid, S.A. Immobilisation of titanium dioxide onto supporting materials in heterogeneous photocatalysis: A review. Appl. Catal. A 2010, 389, 1-8.

85. Zhu, B.; Zou, L. Trapping and decomposing of color compounds from recycled water by $\mathrm{TiO}_{2}$ coated activated carbon. J. Environ. Manag. 2009, 90, 3217-3225.

86. Jin, L.; Dai, B. $\mathrm{TiO}_{2}$ activation using acid-treated vermiculite as a support: Characteristics and photoreactivity. Appl. Surf. Sci. 2012, 258, 3386-3392.

87. Stathatos, E.; Papoulis, D.; Aggelopoulos, C.A.; Panagiotaras, D.; Nikolopoulou, A. $\mathrm{TiO}_{2} /$ palygorskite composite nanocrystalline films prepared by surfactant templating route: Synergistic effect to the photocatalytic degradation of an azo-dye in water. J. Hazard. Mater. 2012, 211, 68-76. 
88. Djafer, L.; Ayral, A.; Ouagued, A. Robust synthesis and performance of a titania-based ultrafiltration membrane with photocatalytic properties. Sep. Purif. Technol. 2010, 75, 198-203.

89. Athanasekou, C.P.; Romanos, G.E.; Katsaros, F.K.; Kordatos, K.; Likodimos, V.; Falaras, P. Very efficient composite titania membranes in hybrid ultrafiltration/photocatalysis water treatment processes. J. Membr. Sci. 2012, 392, 192-203.

90. Romanos, G.E.; Athanasekou, C.P.; Katsaros, F.K.; Kanellopoulos, N.K.; Dionysiou, D.D.; Likodimos, V.; Falaras, P. Double-side active $\mathrm{TiO}_{2}$-modified nanofiltration membranes in continuous flow photocatalytic reactors for effective water purification. J. Hazard. Mater. 2012, 211, 304-316.

91. Damodar, R.A.; You, S.-J.; Chou, H.-H. Study the self cleaning, antibacterial and photocatalytic properties of $\mathrm{TiO}_{2}$ entrapped PVDF membranes. J. Hazard. Mater. 2009, 172, 1321-1328.

92. Liu, L.; Liu, Z.; Bai, H.; Sun, D.D. Concurrent filtration and solar photocatalytic disinfection/degradation using high-performance $\mathrm{Ag} / \mathrm{TiO}_{2}$ nanofiber membrane. Water Res. 2012, 46, 1101-1112.

93. Bedford, N.M.; Pelaez, M.; Han, C.; Dionysiou, D.D.; Steckl, A.J. Photocatalytic cellulosic electrospun fibers for the degradation of potent cyanobacteria toxin microcystin-LR. J. Mater. Chem. 2012, 22, 12666-12674.

94. Chen, Y.J.; Stathatos, E.; Dionysiou, D.D. Microstructure characterization and photocatalytic activity of mesoporous $\mathrm{TiO}_{2}$ films with ultrafine anatase nanocrystallites. Surf. Coat. Technol. 2008, 202, 1944-1950.

95. Chen, Y.J.; Dionysiou, D.D. Bimodal mesoporous $\mathrm{TiO}_{2}-\mathrm{P} 25$ composite thick films with high photocatalytic activity and improved structural integrity. Appl. Catal. B 2008, 80, 147-155.

96. Pelaez, M.; Falaras, P.; Likodimos, V.; Kontos, A.G.; de la Cruz, A.A.; O’Shea, K.; Dionysiou, D.D.

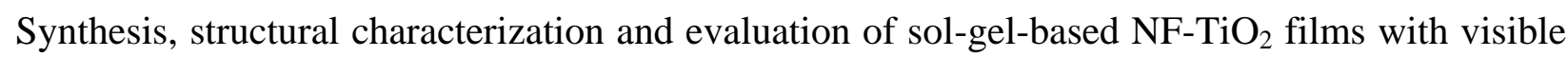
light-photoactivation for the removal of microcystin-LR. Appl. Catal. B 2010, 99, 378-387.

97. Kontos, A.G.; Pelaez, M.; Likodimos, V.; Vaenas, N.; Dionysiou, D.D.; Falaras, P. Visible light induced wetting of nanostructured NF co-doped titania films. Photochem. Photobiol. Sci. 2011, 10, 350-354.

98. Han, C.; Pelaez, M.; Likodimos, V.; Kontos, A.G.; Falaras, P.; O’Shea, K.; Dionysiou, D.D. Innovative visible light-activated sulfur doped $\mathrm{TiO}_{2}$ films for water treatment. Appl. Catal. B 2011, 107, 77-87.

99. Antoniou, M.G.; Nicolaou, P.A.; Shoemaker, J.A.; de la Cruz, A.A.; Dionysiou, D.D. Impact of the morphological properties of thin $\mathrm{TiO}_{2}$ photocatalytic films on the detoxification of water contaminated with the cyanotoxin, microcystin-LR. Appl. Catal. B 2009, 91, 165-173.

100. Pelaez, M.; Falaras, P.; Kontos, A.G.; de la Cruz, A.A.; O’Shea, K.; Dunlop, P.S.M.; Byrne, J.A.; Dionysiou, D.D. A comparative study on the removal of cylindrospermopsin and microcystins from water with $\mathrm{NF}^{-T_{i O}}$-P25 composite films with visible and $\mathrm{UV}$-Vis light photocatalytic activity. Appl. Catal. B 2012, 121, 30-39.

101. Natarajan, T.S.; Thomas, M.; Natarajan, K.; Bajaj, H.C.; Tayade, R.J. Study on UV-LED/TiO 2 process for degradation of rhodamine B dye. Chem. Eng. J. 2011, 169, 126-134. 
102. Natarajan, T.S.; Natarajan, K.; Bajaj, H.C.; Tayade, R.J. Energy efficient uv-led source and $\mathrm{TiO}_{2}$ nanotube array-based reactor for photocatalytic application. Ind. Eng. Chem. Res. 2011, 50, 7753-7762.

103. Natarajan, K.; Natarajan, T.S.; Bajaj, H.C.; Tayade, R.J. Photocatalytic reactor based on UV-LED/TiO 2 coated quartz tube for degradation of dyes. Chem. Eng. J. 2011, 178, 40-49.

104. Nickels, P.; Zhou, H.; Basahel, S.N.; Obaid, A.Y.; Ali, T.T.; Al-Ghamdi, A.A.; El-Mossalamy, E.-S.H.; Ayoubi, A.O.; Lynch, S.A. Laboratory scale water circuit including a photocatalytic reactor and a portable in-stream sensor to monitor pollutant degradation. Ind. Eng. Chem. Res. 2012, 51, 3301-3308.

105. Wang, X.P.; Lim, T.T. Solvothermal synthesis of C-N codoped $\mathrm{TiO}_{2}$ and photocatalytic evaluation for bisphenol a degradation using a visible-light irradiated led photoreactor. Appl. Catal. B 2010, 100, 355-364.

106. Chang, C.Y.; Wu, N.L. Process analysis on photocatalyzed dye decomposition for water treatment with $\mathrm{TiO}_{2}$-coated rotating disk reactor. Ind. Eng. Chem. Res. 2010, 49, 12173-12179.

107. Rao, N.N.; Chaturvedi, V.; Puma, G.L. Novel pebble bed photocatalytic reactor for solar treatment of textile wastewater. Chem. Eng. J. 2012, 184, 90-97.

108. Ji, Z.X.; Callahan, D.M.; Ismail, M.N.; Warzywoda, J.; Sacco, A. Development and characterization of a titanosilicate ETS-10-coated optical fiber reactor towards the photodegradation of methylene blue. J. Photochem. Photobiol. A 2011, 217, 22-28.

109. Kim, M.J.; Choo, K.H.; Park, H.S. Photocatalytic degradation of seawater organic matter using a submerged membrane reactor. J. Photochem. Photobiol. A 2010, 216, 215-220.

110. Suryaman, D.; Hasegawa, K.; Kagaya, S.; Yoshimura, T. Continuous flow photocatalytic treatment integrated with separation of titanium dioxide on the removal of phenol in tap water. $J$. Hazard. Mater. 2009, 171, 318-322.

111. McCullagh, C.; Robertson, P.K.J.; Adams, M.; Pollard, P.M.; Mohammed, A. Development of a slurry continuous flow reactor for photocatalytic treatment of industrial waste water. $J$. Photochem. Photobiol. A 2010, 211, 42-46.

112. Vilar, V.J.P.; Maldonado, M.I.; Oller, I.; Malato, S.; Boaventura, R.A.R. Solar treatment of cork boiling and bleaching wastewaters in a pilot plant. Water Res. 2009, 43, 4050-4062.

113. Remoundaki, E.; Vidali, R.; Kousi, P.; Hatzikioseyian, A.; Tsezos, M. Photolytic and photocatalytic alterations of humic substances in UV $(254 \mathrm{~nm})$ and solar cocentric parabolic concentrator (CPC) reactors. Desalination 2009, 248, 843-851.

114. Benotti, M.J.; Stanford, B.D.; Wert, E.C.; Snyder, S.A. Evaluation of a photocatalytic reactor membrane pilot system for the removal of pharmaceuticals and endocrine disrupting compounds from water. Water Res. 2009, 43, 1513-1522.

115. Zayani, G.; Bousselmi, L.; Mhenni, F.; Ghrabi, A. Solar photocatalytic degradation of commercial textile azo dyes: Performance of pilot plant scale thin film fixed-bed reactor. Desalination 2009, 246, 344-352.

116. Vargas, R.; Nunez, O. Photocatalytic degradation of oil industry hydrocarbons models at laboratory and at pilot-plant scale. Sol. Energy 2010, 84, 345-351. 
117. Dionysiou, D.D.; Balasubramanian, G.; Suidan, M.T.; Khodadoust, A.P.; Baudin, I.; Laine, M. Rotating disk photocatalytic reactor: Development, characterization, and evaluation for the destruction of organic pollutants in water. Water Res. 2000, 34, 2927-2940.

118. Dionysiou, D.; Khodadoust, A.P.; Kern, A.M.; Suidan, M.T.; Baudin, I.; Laine, J.M. Continuous-mode photocatalytic degradation of chlorinated phenols and pesticides in water using a bench-scale $\mathrm{TiO}_{2}$ rotating disk reactor. Appl. Catal. B 2000, 24, 139-155.

119. Wang, C.; Sun, L.; Yun, H.; Li, J.; Lai, Y.; Lin, C. Sonoelectrochemical synthesis of highly photoelectrochemically active $\mathrm{TiO}_{2}$ nanotubes by incorporating cds nanoparticles. Nanotechnology 2009, 20, 295601.

120. Bach, U.; Lupo, D.; Comte, P.; Moser, J.E.; Rtel, F.W.; Salbeck, J.; Spreitzer, H.; Grätzel, M. Solid-state dye-sensitized mesoporous $\mathrm{TiO}_{2}$ solar cells with high photon-to-electron conversion efficiencies. Nature 1998, 395, 583-585.

121. Barolo, G.; Livraghi, S.; Chiesa, M.; Paganini, M.C.; Giamello, E. Mechanism of the photoactivity under visible light of $\mathrm{N}$-doped titanium dioxide. Charge carriers migration in irradiated $\mathrm{N}-\mathrm{TiO}_{2}$ investigated by electron paramagnetic resonance. J. Phys. Chem. C 2012, 116, 20887-20894.

122. Kamegawa, T.; Sonoda, J.; Sugimura, K.; Mori, K.; Yamashita, H. Degradation of isobutanol diluted in water over visible light sensitive vanadium doped $\mathrm{TiO}_{2}$ photocatalyst. J. Alloy. Compd. 2009, 486, 685-688.

123. Cui, L.; Wang, Y.; Niu, M.; Chen, G.; Cheng, Y. Synthesis and visible light photocatalysis of Fe-doped $\mathrm{TiO}_{2}$ mesoporous layers deposited on hollow glass microbeads. J. Solid State Chem. 2009, 182, 2785-2790.

124. Kuvarega, A.T.; Krause, R.W.M.; Mamba, B.B. Nitrogen/palladium-codoped $\mathrm{TiO}_{2}$ for efficient visible light photocatalytic dye degradation. J. Phys. Chem. C 2011, 115, 22110-22120.

125. Wodka, D.; Bielanska, E.; Socha, R.P.; Elzbieciak-Wodka, M.; Gurgul, J.; Nowak, P.; Warszynski, P.; Kumakiri, I. Photocatalytic activity of titanium dioxide modified by silver nanoparticles. Appl. Mater. Inter. 2010, 2, 1945-1953.

126. Kusiak-Nejman, E.; Janus, M.; Grzmil, B.; Morawski, A.W. Methylene blue decomposition under visible light irradiation in the presence of carbon-modified $\mathrm{TiO}_{2}$ photocatalysts. $J$. Photochem. Photobiol. A 2011, 226, 68-72.

127. Liu, G.; Wang, X.; Chen, Z.; Cheng, H.-M.; Lu, G.Q. The role of crystal phase in determining photocatalytic activity of nitrogen doped $\mathrm{TiO}_{2}$. J. Colloid Interface Sci. 2009, 329, 331-338.

128. Gohin, M.; Maurin, I.; Gacoin, T.; Boilot, J.P. Photocatalytic activity of mesoporous films based on n-doped $\mathrm{TiO}_{2}$ nanoparticles. J. Mater. Chem. 2010, 20, 8070-8077.

129. Rockafellow, E.M.; Stewart, L.K.; Jenks, W.S. Is sulfur-doped $\mathrm{TiO}_{2}$ an effective visible light photocatalyst for remediation? Appl. Catal. B 2009, 91, 554-562.

130. Song, S.; Tu, J.J.; He, Z.Q.; Hong, F.Y.; Liu, W.P.; Chen, J.M. Visible light-driven iodine-doped titanium dioxide nanotubes prepared by hydrothermal process and post-calcination. Appl. Catal. A 2010, 378, 169-174.

131. Ma, N.; Quan, X.; Zhang, Y.; Chen, S.; Zhao, H. Integration of separation and photocatalysis using an inorganic membrane modified with $\mathrm{Si}$-doped $\mathrm{TiO}_{2}$ for water purification. J. Membr. Sci. 2009, 335, 58-67. 
132. Hewer, T.L.R.; Souza, E.C.C.; Martins, T.S.; Muccillo, E.N.S.; Freire, R.S. Influence of neodymium ions on photocatalytic activity of $\mathrm{TiO}_{2}$ synthesized by sol-gel and precipitation methods. J. Mol. Catal. A 2011, 336, 58-63.

133. Van Grieken, R.; Marugan, J.; Sordo, C.; Martinez, P.; Pablos, C. Photocatalytic inactivation of bacteria in water using suspended and immobilized silver-TiO ${ }_{2}$. Appl. Catal. B 2009, 93, 112-118.

134. Liga, M.V.; Bryant, E.L.; Colvin, V.L.; Li, Q.L. Virus inactivation by silver doped titanium dioxide nanoparticles for drinking water treatment. Water Res. 2011, 45, 535-544.

135. Choi, W.; Termin, A.; Hoffmann, M.R. The role of metal ion dopants in quantum-sized $\mathrm{TiO}_{2}$ : Correlation between photoreactivity and charge carrier recombination dynamics. J. Phys. Chem. 1994, 98, 13669-13679.

136. Zhang, C.; Gu, L.; Lin, Y.; Wang, Y.; Fu, D.; Gu, Z. Degradation of x-3b dye by immobilized $\mathrm{TiO}_{2}$ photocatalysis coupling anodic oxidation on BDD electrode. J. Photochem. Photobiol. A 2009, 207, 66-72.

137. Paschoal, F.M.M.; Pepping, G.; Boldrin Zanoni, M.V.; Anderson, M.A. Photoelectrocatalytic removal of bromate using $\mathrm{Ti} / \mathrm{TiO}_{2}$ coated as a photocathode. Environ. Sci. Technol. 2009, 43, 7496-7502.

138. Daghrir, R.; Drogui, P.; Ka, I.; El Khakani, M.A. Photoelectrocatalytic degradation of chlortetracycline using $\mathrm{Ti} / \mathrm{TiO}_{2}$ nanostructured electrodes deposited by means of a pulsed laser deposition process. J. Hazard. Mater. 2012, 199, 15-24.

139. Torres-Palma, R.A.; Nieto, J.I.; Combet, E.; Petrier, C.; Pulgarin, C. An innovative ultrasound, $\mathrm{Fe}^{2+}$ and $\mathrm{TiO}_{2}$ photoassisted process for bisphenol Amineralization. Water Res. 2010, 44, 2245-2252.

140. Suryaman, D.; Hasegawa, K. Biological and photocatalytic treatment integrated with separation and reuse of titanium dioxide on the removal of chlorophenols in tap water. J. Hazard. Mater. 2010, 183, 490-496.

141. Chebli, D.; Fourcade, F.; Brosillon, S.; Nacef, S.; Amrane, A. Supported photocatalysis as a pre-treatment prior to biological degradation for the removal of some dyes from aqueous solutions; acid red 183, biebrich scarlet, methyl red sodium salt, orange II. J. Chem. Technol. Biotechnol. 2010, 85, 555-563.

142. Yahiat, S.; Fourcade, F.; Brosillon, S.; Amrane, A. Photocatalysis as a pre-treatment prior to a biological degradation of cyproconazole. Desalination 2011, 281, 61-67.

143. Yahiat, S.; Fourcade, F.; Brosillon, S.; Amrane, A. Removal of antibiotics by an integrated process coupling photocatalysis and biological treatment-case of tetracycline and tylosin. Int. Biodeterior. Biodegrad. 2011, 65, 997-1003.

144. Laera, G.; Chong, M.N.; Jin, B.; Lopez, A. An integrated $\mathrm{mbr}^{-\mathrm{TiO}_{2}}$ photocatalysis process for the removal of carbamazepine from simulated pharmaceutical industrial effluent. Bioresour. Technol. 2011, 102, 7012-7015.

145. Chen, K.C.; Wang, Y.H.; Lu, Y.C. Treatment of polluted water for reclamation using photocatalysis and constructed wetlands. Catal. Today 2011, 175, 276-282.

(C) 2012 by the authors; licensee MDPI, Basel, Switzerland. This article is an open access article distributed under the terms and conditions of the Creative Commons Attribution license (http://creativecommons.org/licenses/by/3.0/). 